
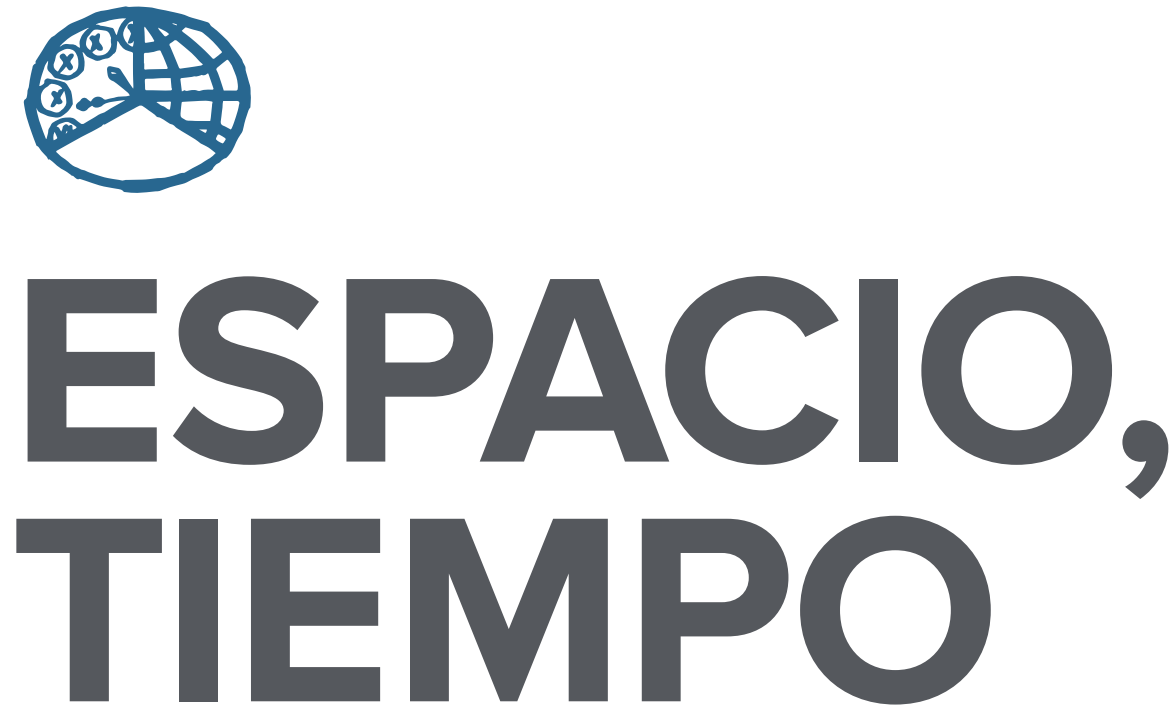

AÑO 2013

NUEVA ÉPOCA

ISSN 1130-4715

E-ISSN 2340-1478
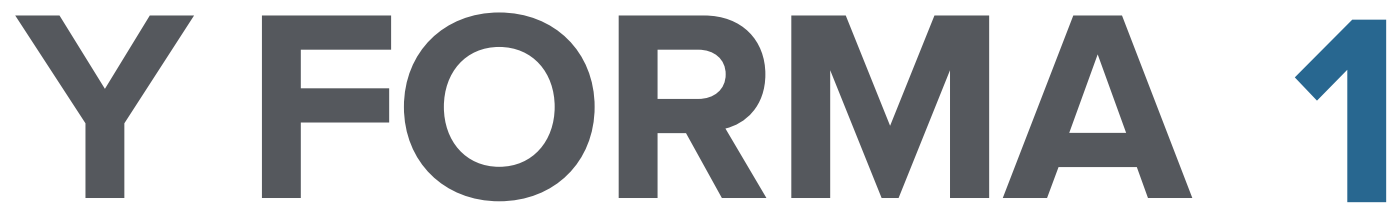

SERIE VII HISTORIA DEL ARTE

REVISTA DE LA FACULTAD DE GEOGRAFÍA E HISTORIA 

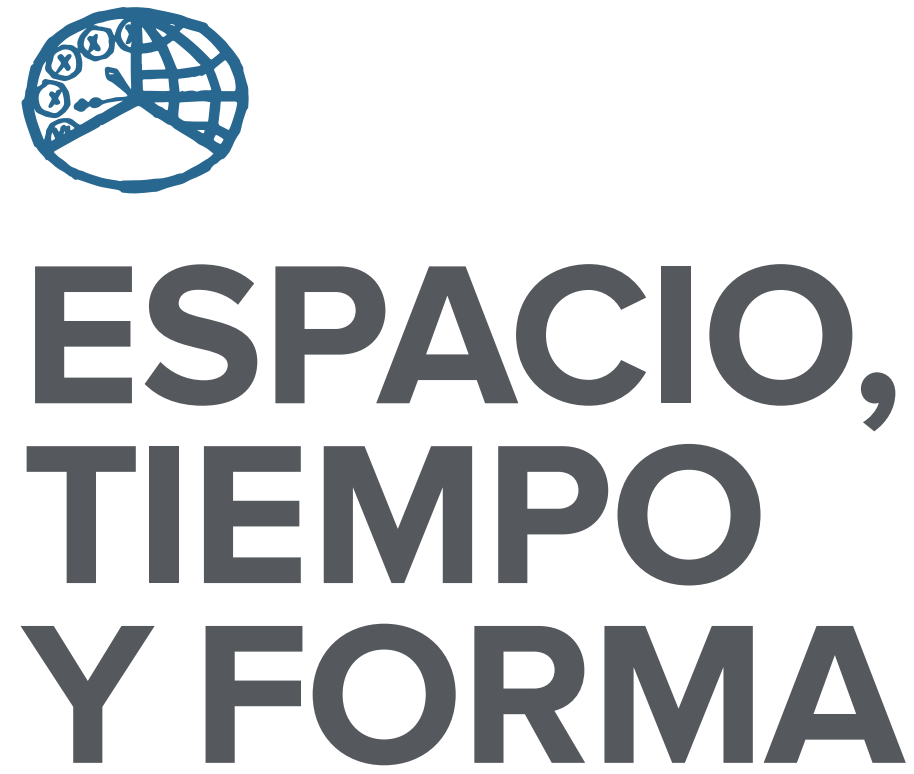

AÑO 2013

NUEVA ÉPOCA

ISSN $1130-4715$

E-ISSN 2340-1478

SERIE VII HISTORIA DEL ARTE

REVISTA DE LA FACULTAD DE GEOGRAFÍA E HISTORIA

http://dx.doi.org/10.5944/etfvii.1.2013

\section{UกED}

UNIVERSIDAD NACIONAL DE EDUCACIÓN A DISTANCIA 
La revista Espacio, Tiempo y Forma (siglas recomendadas: ETF), de la Facultad de Geografía e Historia de la UNED, que inició su publicación el año 1988, está organizada de la siguiente forma:

$$
\begin{aligned}
& \text { SERIE I - Prehistoria y Arqueología } \\
& \text { SERIE II - Historia Antigua } \\
& \text { SERIE III - Historia Medieval } \\
& \text { SERIE IV - Historia Moderna } \\
& \text { SERIE V - Historia Contemporánea } \\
& \text { SERIE VI - Geografía } \\
& \text { SERIE VII - Historia del Arte }
\end{aligned}
$$

Excepcionalmente, algunos volúmenes del año 1988 atienden a la siguiente numeración:

$$
\begin{aligned}
& \mathrm{N}^{\circ} 1 \text { - Historia Contemporánea } \\
& \mathrm{N}^{\circ} 2 \text { - Historia del Arte } \\
& \mathrm{N}^{\circ} 3 \text { - Geografía } \\
& \mathrm{N} .^{\circ} 4 \text { - Historia Moderna }
\end{aligned}
$$

ETF no se solidariza necesariamente con las opiniones expresadas por los autores.

Espacio, Tiempo y Forma, Serie vII está registrada e indexada, entre otros, por los siguientes Repertorios Bibliográficos y Bases de Datos: DICE, ISOC (CINDOC), RESH, IN-RECH, Dialnet, e-spacio, UNED, CIRC, MIAR, FRANCIS, PIO, Ulrich's, SUDOC, 2DB, ERIH (ESF).

\author{
UNIVERSIDAD NACIONAL DE EDUCACIÓN A DISTANCIA \\ Madrid, 2013 \\ SERIE VII · HISTORIA DEL ARTE (NUEVA ÉPOCA) N. ${ }^{\circ} 1,2013$ \\ ISSN $1130-4715 \cdot$ E-ISSN 2340-1478 \\ DEPÓSITO LEGAL \\ $M-21.037-1988$ \\ URL \\ ETF VII · HISTORIA DEL ARTE · http://revistas.uned.es/index.php/ETFVII \\ DISEÑO Y COMPOSICIÓN \\ Ángela Gómez Perea · http://angelagomezperea.com \\ Sandra Romano Martín · http://sandraromano.es \\ Impreso en España · Printed in Spain
}

(c) (1) (8) Esta obra está bajo una licencia Creative Commons

Reconocimiento-NoComercial 4.0 Internacional. 


\title{
CARPINTERO Y MAESTRO CONSTRUCTOR EN LA ARQUITECTURA GÓTICA VALENCIANA (SIGLOS XIV-XV)
}

\author{
CARPENTERS AND BUILDING MASON \\ IN THE GOTHIC ARCHITECTURE \\ IN VALENCIA $\left(14^{\mathrm{TH}}-15^{\text {TH }}\right.$ CENTURIES)
}

\author{
Teresa Izquierdo Aranda ${ }^{1}$ \\ Recibido: 28/02/2013 - Aprobado: 18/06/2013 \\ http://dx.doi.org/10.5944/etfvii.1.2013.5350
}

\section{Resumen}

Desde finales del siglo xilı hasta el último cuarto del siglo xv, la corporación de oficio de carpinteros de Valencia englobaba todas aquellas especialidades vinculadas con el trabajo en madera, por ello incluso los albañiles estaban agrupados en este colectivo. En principio, las labores desempeñadas en la construcción proporcionaban el punto de encuentro, aunque la creciente especificidad profesional y las favorables condiciones económicas de mediados del siglo xv estimularon las aspiraciones de autonomía de ciertos brazos. En este artículo analizaremos en concreto las relaciones entre la carpintería y la obra de vila para esclarecer las causas de su emancipación y efectuar un seguimiento de la trayectoria social y profesional del oficio.

\section{Palabras clave}

carpintería; oficios de la construcción; corporaciones de oficio; arquitectura gótica; desarrollo técnico

\begin{abstract}
Since the end of the $12^{\text {th }}$ century until the last quarter of the $15^{\text {th }}$ century, the carpenters' guild in Valencia enclosed all workers with activities related to wood craft, thus even masons were grouped in this collective. Initially, the tasks performed at the construction place provided the meeting point for all of them, but the increasing specialization of their professions and the favourable economical conditions in the mid-I $5^{\text {th }}$ century stimulated some branches to become autonomous. In this article we will analyse in depth the relationship between carpentry and building in order to enlighten the causes of their emancipation, and we will follow the social and professional course of the trade.
\end{abstract}

\section{Keywords}

carpentry; building trades; guilds; Gothic architecture; technical development

\footnotetext{
1. Doctora en Historia del Arte. Universidad de Valencia (teresa.izquierdo@uv.es).
} 


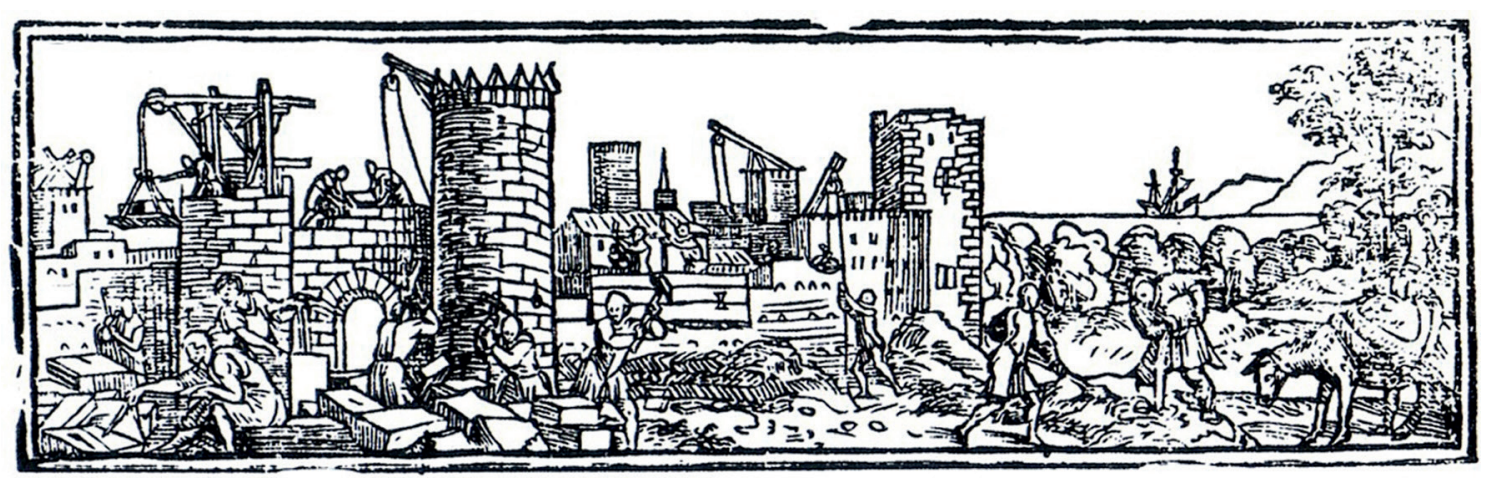

FIGURA 1

Pere Antoni Beuter, Primera parte de la Crónica General de Toda España y especialmente del Reyno de Valencia, 1546.

\section{INTRODUCCIÓN}

La construcción constituía el punto de encuentro entre maestros de obra de especialidades distintas. En principio, la materia de trabajo distinguía al carpintero del cantero o pedrapiquer, pero a nivel laboral la afinidad de los empeños del albañil, el operarius operis ville, con la carpintería llevó, desde un primer momento, a la inserción de este sector en la disciplina del oficio de carpintero ${ }^{2}$. Así, ya en las primeras ordenanzas aprobadas en I424 se contemplaba al obrero de villa entre los brazos de la corporación'. Porque, a pie de obra, el carpintero no era un simple operario especializado, de su incumbencia era la construcción e instalación de las estructuras auxiliares oportunas y de retirarlas una vez asentada la fábrica ${ }^{4}$. Desde esta perspectiva, no resulta extraño que para aclarar la condición del carpintero medieval en la construcción, se haya subrayado la usual colaboración entre el carpintero, encargado de diseñar la estructura, y el albañil, responsable de los trabajos de cimentación y la mazonería (FIGURA I).

2. PACEY, A.: Medieval Architectural drawing. English craftsmen's methods and their later resistance (c. 1200-1700). Stroud, Tempus, 2007, p. 87.

3. Izquierdo Aranda, T.: La fusteria a la València medieval (1238-1520), Castelló de la Plana, Publicacions de la Universitat Jaume I, 2014. Las primeras referencias a la corporación datan de 1290, no obstante, las primeras ordenanzas aprobadas de carácter propiamente profesional datan de 1424. Estos primeros estatutos inauguraron una activa política corporativa encaminada a normalizar la profesión. El 10 de abril de 1424 elevaron a Alfonso el Magnánimo un nuevo código estatutario, en el que se obligaba «a todo carpintero, cajero, cofrero, maestro de hacha, obrero de villa, botero, aladrero, tornero, y cualquier otra persona de cualquier ley o condición sea que en adelante obrasen de madera o usaran el hacha o la sierra en la Ciudad de Valencia y contribución de aquella, aunque no sea cofrade de la dicha cofradía o limosna paguen y sean considerados de pagar por cada año a la caja». Era el primer listado de los componentes del oficio, en el que se intentaba delimitar las especialidades que debían ceñirse a la disciplina corporativa, además de establecer el pago de una cuota anual que se convirtió en una auténtica licencia laboral, que lo capacitaría para trabajar en la capital y en su término. Con esta medida, se subrayaba el radio de implantación económica y jurídica de la corporación.

4. Collura, M.: Architettura in legno. Palermo, Editore Lo Monaco, 1968, p. 123.

5. Solís, J.A. «La economía de la construcción en la Edad Media», en GRACIANI, A. (ed.): La técnica de la arquitectura en la antigüedad. Sevilla, Universidad de Sevilla, 1999, p. 140. 
Un caso significativo de su participación en las obras se advierte en el transcurso de la construcción de la catedral de Exeter entre 1316 y I342, período en el que el maestro Tomás de Witney no sólo se encargó de finalizar el levantamiento de la nave central, de coordinar los diseños de la tracería de los ventanales y de la galería entre el altar y el coro, sino que participó en la ejecución de la armadura para la que incluso aconsejó la especie apropiada ${ }^{6}$. Un ejemplo más cercano lo ofrece el viaje emprendido en octubre de I4I5 por el maestro de las obras de la catedral de Barcelona Bartomeu Gual, al desplazarse a Valencia acompañado por el carpintero Joan Ayigues y un sobrino suyo para ver el modelo de la seo valenciana. La presencia del carpintero se comprende por el interés de examinar los técnicos empleados a pie de obra y por la eventual reproducción a escala de la obra elegida como inspiración ${ }^{7}$. Este tipo de colaboraciones eran lógicas entre los maestros responsables de la realización del proyecto, por lo que se extendían indistintamente entre artífices de distintas especialidades. Esta interpenetración generó una circunstancia característica de la arquitectura medieval: esa versatilidad manifiesta de maestros capaces de llevar a cabo operaciones de muy diverso calibre ${ }^{8}$.

En la obra el carpintero era un trabajador capaz de desplegar un amplio abanico de operaciones. Se encargaba de elaborar cimbras, andamios, de construir porches y tarimas, de grúas para la elevación de materiales, además de realizar reparaciones e intervenciones esporádicas de carácter menor, como la reparación de útiles. Por ello, si en Valencia la corporación de San Lucas congregaba a carpinteros y albañiles, en otras ciudades de la Corona de Aragón, como Girona, la cofradía de los Santos Cuatro Coronados reunía a maestros de casas, picapedreros, carpinteros y escultores ${ }^{9}$. Del mismo modo, en Zaragoza la popularmente conocida como «cofradía de los cinco oficios» englobó a carpinteros, torneros, boteros, canteros y albañiles hasta su disolución en $1619^{\text {Io }}$. En la capital aragonesa esta tendencia se corroboró además en la asociación fundada en torno a 1503 por los artífices musulmanes a raíz de la expulsión de los moriscos de Castilla, bajo el amparo de Fernando el Católico ${ }^{\text {II }}$. Este «Officio de maestros e obreros de casas e cualesquiera obras de aljez, rajola e fusta, de puertas, ventanas e otras obras de fusta» englobaba cuarenta maestros

6. Thomas de Witney (1270-1342) trabajó como maestro de obra en las catedrales de Winchester, Wells y Exeter, era reconocido como carpintero por su intervención en el diseño del Pilgrim's Hall de Winchester (1310). Sobre la figura de este artífice véase MorRIS, R.K.: «Thomas de Witney at Exeter, Wells and Winchester», in KELLY, F. (ed.): Medieval Art and Architecture at Exeter Cathedral. London, British Archaeological Association, 1991, pp. 57-84.

7. Montero, E.: «El sentido y uso de la mostra en los oficios artísticos. Valencia, 1390-1450», Boletín del Museo e Instituto Camón Aznar, 94 (2004), pp. 239-240. La referencia a la visita se toma de CARRERAS CANDI, F.: «Les obres de la catedral de Barcelona», Butlletí de la Reial Acadèmia de Bones Lletres, 7 (1914), p. 313.

8. Serra Desfilis, A.: «Promotores, tradiciones e innovación en la arquitectura valenciana del siglo XV», Goya, 334 (2011), pp. 64-68

9. Domènech I Casadevall, G.: Els oficis de la construcció a Girona, 1419-1833. Ofici i confraria. Mestres de cases, picapedrers, fusters i escultors a Girona. Girona, Institut d'Estudis Gironins, 2001, pp. 13-15.

10. Redondo, G.: Las Corporaciones de artesanos de Zaragoza en el siglo xVII. Zaragoza, Institución Fernando el Católico, 1982, pp. 91-92. Expósıto SebAStiÁN, M.: «El gremio de albañiles de Zaragoza (1775-1806)», Artigrama, 2 (1985), p. 162

11. Gómez, M.C.: Arquitectura civil en Zaragoza en el siglo xvı. Zaragoza, Ayuntamiento de Zaragoza. Delegación de Relaciones Municipales, 1987-1988, vol. I, p. 70. 
FIGURA 2

Gérard de Horenbout y Simon Bening, Libro de Horas de Juana I de Castilla, $1500 \mathrm{ca} .$, Londres, British Library, Ms. 35313 , f. 34 r.

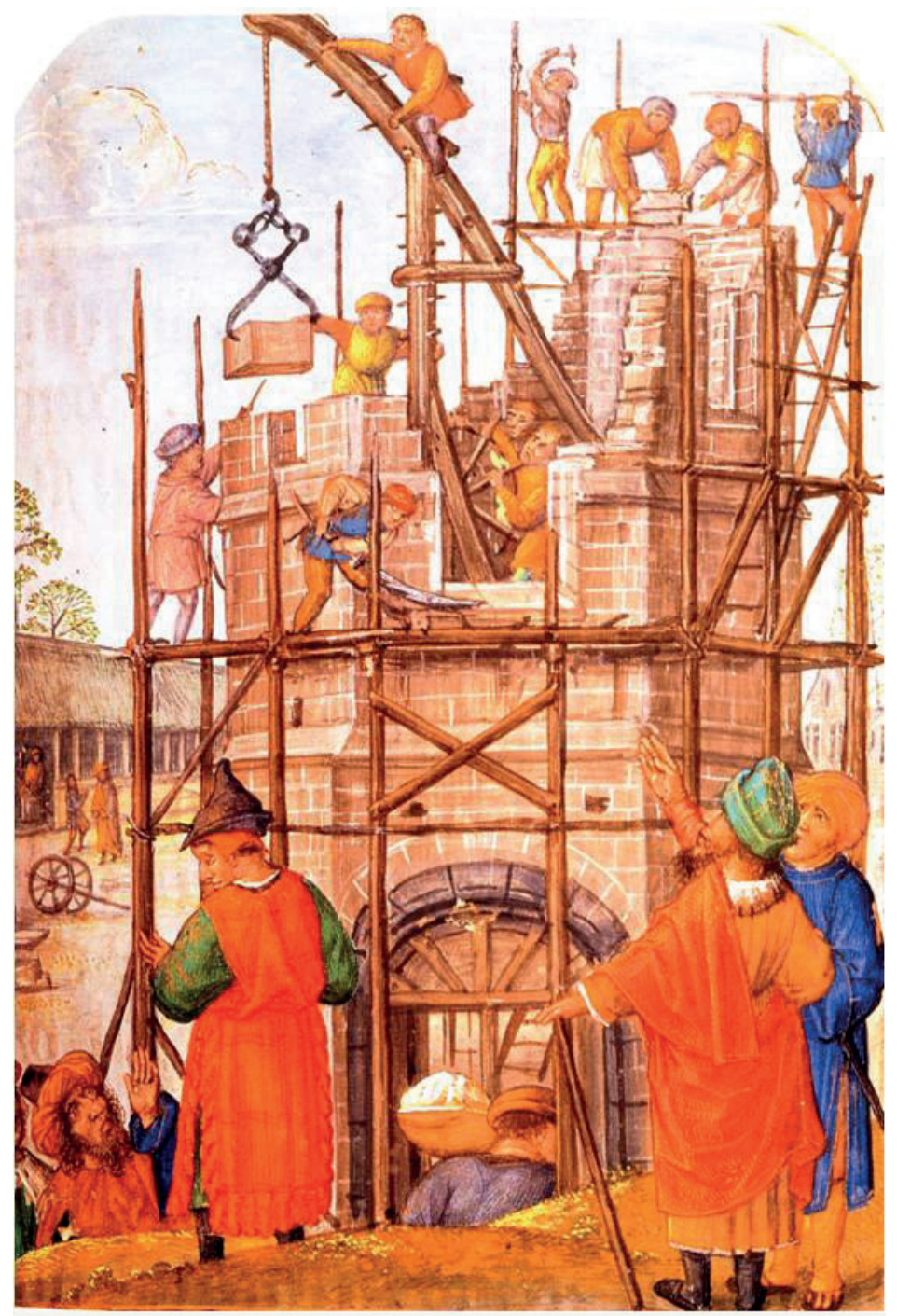

dedicados a la edificación, al trabajo en yeso y a la carpintería, y constituían casi un tercio de las familias musulmanas censadas en la ciudad en I495' (FIGURA 2).

Al evocar la idiosincrasia de la carpintería medieval en Asturias, José M. Legazpi extraía ya una primera clasificación resultada de la diferenciación entre la de exterior y la de taller ${ }^{13}$. Se trataba en definitiva de la distinción entre la carpintería mecánica, propia de la construcción y la ingeniería, respecto a los sectores dedicados a la manufactura o el mobiliario. La diferencia palmaria entre ambas modalidades fue bien recogida por la corporación de oficios de la carpintería de Mallorca

12. Gómez, M.C.: «Las Artes en Aragón durante el reinado de Fernando el Católico (1479-1516)», en La arquitectura civil en Aragón. Zaragoza, Institución Fernando el Católico, 1993, p. 112.

13. LegAZPI, J.M.: Ingenios de madera. Carpintería mecánica medieval aplicada a la agricultura. Oviedo, Caja de Ahorros de Asturias - Ministerio de Agricultura, Pesca y Alimentación, 1991, pp. 42-44. 
en I499, al distinguir entre los carpinteros grossers o de obra gruesa, constructores de plataformas, andamios, toneles y útiles agrícolas, y aquellos de obra prima o primaters, dedicados fundamentalmente a la fabricación de cajas, cofres y mobiliario. Mediante esta distinción de base se definían unos parámetros similares a la clasificación de la corporación valenciana ${ }^{\text {I4 }}$.

La necesaria concurrencia de la madera en la obra superaba los márgenes del mobiliario o de los elementos decorativos que, al acabar la construcción, revestirían su interior ${ }^{15}$. Las empresas edilicias ofrecían el espacio idóneo para compartir experiencias, favorecían el contacto entre las distintas especialidades de la construcción y, por tanto, el trasvase de ideas, saberes y técnicas. La familiaridad del carpintero con la arquitectura se basaba en su capacidad multidisciplinar, por su dominio del instrumental adecuado en el tratamiento de una amplia serie de materiales que lo capacitarían para dirigir proyectos arquitectónicos. Un caso célebre de esta particular contribución de la carpintería en la edificación la encontramos por ejemplo en el sistema de vigas maestras introducidas en el palacio Ca' d'Oro de Venecia por los carpinteros Zane y Antonio Rossi para garantizar la estabilidad del edificio ${ }^{16}$.

\section{ACTIVIDADES ASOCIADAS AL PROGRAMA CONSTRUCTIVO}

A nivel laboral, independientemente de que el carpintero fuese el caput magister o de que trabajara a las órdenes de un maestro de otra rama de la construcción, pueden señalarse varias áreas de colaboración conjunta ${ }^{17}$. En primer lugar, la elaboración de «muestras», trazadas en papel o pergamino, o tridimensionales, modeladas en yeso o madera. Estos bocetos y maquetas eran trabajos artísticos en sí mismos, que requerían gran pericia, como muestran los ejemplares presentados por Sebald Schreyer en 1487 a las autoridades del hospital del Santo Espíritu de Nuremberg o por Burkhard Engelberg en 1507 para la nueva torre de la catedral de Berna ${ }^{18}$. En la arquitectura valenciana se hallan ampliamente documentados, un ejemplo temprano fue el trazado marcado en las eras de Ruzafa por Andreu Julià en abril de I38I al inicio de las obras del campanario del Micalet, que tal vez reproducían el diseño del campanario de la catedral de Lérida que él mismo había dibujado en $1377^{19}$.

14. Domenge I Mesquida, J.: «Entorn als oficis artístics de Mallorca. Una aproximació als treballs i ocupacions dels artistes medievals (segles XIV-XVI)», en BARCELó CRESPÍ, M. (ed.): La manufactura urbana i els menestrals (segles XIII-XVI). Actes de les Ix Jornades d'Estudis Històrics Locals. Palma, 21-23 de novembre de 1990. Palma de Mallorca, Institut d'Estudis Baleàrics, pp. 381-398.

15. IzQUiERdo ARANDA, T.: op. cit., 2014, pp. 300-305. Salvo en aquellas especialidades claramente diferenciadas como los torneros, los cajeros o los constructores de botas, en la documentación valenciana el calificativo genérico de carpintero se aplicaba a todos aquellos maestros cuya actividad preferente era la construcción. En ella, podían dedicarse tanto a la construcción de plataformas y elementos auxiliares, como a aserrar madera mediante el alquiler de sus sierras, o al diseño y elaboración de pórticos o techumbres, batientes de puertas y ventanas y otros elementos de mobiliario.

16. Coldstream, N.: Medieval architecture. Oxford, Oxford University Press, 2002, pp. 108-110.

17. Coppola, G.: La costruzione del medioevo. Pratola Serra, Sellino Editore, 2000, pp. 19-20.

18. Coldstream, N.: op. cit., p. 79.

19. Sanchís Sivera, J.: La catedral de Valencia, Valencia, Imprenta Fco. Vives Mora, 1909, p. 95 
Respecto a los bocetos trazados sobre pergamino, uno de los primeros ejemplos fue la propuesta que Joan Franch dibujó para renovar la sillería del coro de la catedral de Valencia en 1392. El proyecto fue desestimado por el cabildo, que intentó sin éxito contratar a Guillem Solivella, entonces maestro de obras de la catedral de Lleida. En I4I5, en encargó recayó finalmente en Jaume Esteve, al que se le exigía que la obra «en todas sus partes sea buena, bella y notable, y bien enlevada así com corresponde a la seo, y que en hacer aquella el dicho maestro haya buenos y aptos maestros y suficientes». Al mismo tiempo, se le advertía que debía ceñirse a lo «dibujado y pintado en un gran pergamino», posiblemente uno de los dibujos propuestos por Guillem Solivella en I394 y 1397. Para valorar la excelencia de su labor se designaba ya a Pere Balaguer, maestro de la catedral, y al orfebre Bartomeu Cosollà $^{20}$. La presencia de la muestra en esta obra es un ejemplo del interés de los promotores por su proyecto, del que el boceto constituía una pieza esencial. Entre los modelos conservados en la Corona de Aragón, el más antiguo corresponde a una traza de 1368 de la planta del campanario de la Colegiata de San Félix de Girona sobre papel, que esboza la forma y las dimensiones del futuro edificio ${ }^{21}$. Otro ejemplo fueron los bocetos realizados en pergamino por Pere Balaguer en marzo de 1395 para el portal de Serranos, posiblemente a raíz del viaje que los jurados de Valencia le financiaron en 1392 por diversas ciudades catalanas, para que examinase modelos distintos que pudiesen servir como ejemplo ${ }^{22}$.

En cambio, en el transcurso de las labores se empleaban plantillas, como los «moldes de los portales» que hizo para las torres de Serranos, cuya naturaleza o función desconocemos, pero de su valor nos informa el encargo al carpintero Domingo Beneyto que, junto a dos peones, debía «recorrer la terraza» de la casa de Joan de Bordell (que se empleaba como base de las operaciones) para recuperar los moldes perdidos por un olvido del maestro. Entre los materiales empleados, era frecuente el uso de papel, almidón y cola de gelatina para maquetas en tres dimensiones, como la que preparó el maestro picapedrero Francesc Tona en I40o para la nueva construcción del Puente de los Catalanes de Valencia ${ }^{23}$. Cuando el soporte era la madera el modelo podía ser tridimensional, como la muestra de confeccionada por Jaume Gallent, maestro de obras de la ciudad, para la nova torre que coronaría la Cámara de los Ángeles del Palacio del Real en I44I, que atestigua su autoridad en el diseño arquitectónico ${ }^{24}$. Su importancia convirtió el trazado en una parte esencial

20. Citado por SANChís Sivera, J.: «La escultura valenciana en la Edad Media: notas para su historia», Archivo de Arte Valenciano, 10, pp. 5-6. La obra ha sido estudiada en profundidad por MIQUEL JUAN, M.: «El coro de la catedral de Valencia (1384-1395). La introducción de nuevos elementos decorativos del gótico internacional en Valencia», en Serra, A. (ed.): Arquitectura en construcción en Europa en época medieval y moderna. Valencia, 2010, pp. 349-376.

21. El dibujo se atribuye a Pere Sacoma. Reproducido en el catálogo de la exposición La catedral de Girona.L'obra de la Seu. Girona, Fundació La Caixa, 2003, p. 180. Serra, A.: «Conocimiento, traza e ingenio en la arquitectura valenciana del siglo XV», Anales de Historia del Arte, 22 (2012), p. 195.

22. Archivo Municipal de Valencia (AMv), Sotsobreria de Murs i Valls, $d^{3}-5, f .5$ r, 157 r. Se recomienda el estudio sobre el papel de las muestras y modelos elaborado por SERRA, A.: op. cit., 2012, pp. 184-196.

23. AMv, Sotsobreria de Murs i Valls, $d^{3}-13$, f. 140 v.

24. Serra, A.: «El mestre de les obres de la ciutat de València (1370-1480)», en YARZA, J. \& Fité, F. (eds.): L'artista-artesà medieval a la Corona d'Aragó. Actes. Lleida 14, 15 i 16 de gener de 1998. Lleida, Universitat de Lleida - Institut d'Estudis Ilerdencs, p. 413. El encargo de la maqueta lo mencionaba ya SANCHIS SiverA, J.: op. cit., 1925, p. 42. El registro lo transcribió íntegramente SÁNCHEZ VERDUCH, M.M.: El maestro de obras o la práctica de la arquitectura 
de las tareas del maestro constructor, especialmente en los siglos XIV y xv, cuando los clientes solicitaban dibujos de las propuestas y las muestras ejercían como ejemplos visuales que servían para explicar de un modo gráfico las particularidades de la obra $^{25}$. El empleo de planos y bocetos en la arquitectura medieval está documentado desde el siglo ix en el plano de la abadía de Sant Gall, pero no sería hasta el siglo xiv cuando empieza a generalizarse su uso, debido en parte a la mayor complejidad de las estructuras, que hacía necesaria su muestra a los promotores, interesados para conocer los detalles de las obras que patrocinaban ${ }^{26}$.

De este modo, en los contratos es habitual encontrar referencias a estos modelos, que debían copiarse e incluso imitarse. Así se percibe, en I380, durante la construcción de la capilla del castillo de Hertford, cuando se encomendaba al carpintero Guillermo de Wyntingham seguir el planteamiento de un «diseño copiado en duplicado ${ }^{27}$. La presencia de la muestra en el momento de acordar el contrato confirma su valor didáctico para explicar a los promotores detalles estructurales complejos, a quienes planteaba incluso la posibilidad de intervenir en la toma de decisiones. Un caso elocuente en este sentido fue el viaje del carpintero Joan Bonet a Sicilia el 20 de febrero de I434 «con las muestras de las cuatro torres» para enseñarlas al rey y concertar el proyecto para el Real, en especial de la torre sobre la mencionada Cámara de los Ángeles ${ }^{28}$. Más allá de la propia función didáctica, muchas de estas modelos tenían un valor legal, se mencionan al contratar la obra como garantía del modelo a seguir ${ }^{29}$. Así, cuando en marzo de I4I2 los jurados de Valencia contrataban la talla de los modillones de la Cambra Daurada de la antigua Casa de la Ciudad con los escultores Andreu Sanou y Joan Llobet, se indica explícitamente que las figuras de los profetas que decorarían las ménsulas de menor tamaño habrían de tallarse según los cuatro que ya obrados y presentados por «muestra» $3^{3}$.

Estos ejemplares eran apreciados y guardados con recelo, lo que llevó incluso a incluir cláusulas en los contratos por las que el maestro debía devolver a la obra los bocetos, plantillas o maquetas utilizadas en el curso de los trabajos ${ }^{3 \mathrm{I}}$. Este valor de la muestra explica la compra a la viuda y al padre de Antoni Dalmau en I453 de «la bella muestra» elaborada para el pináculo de la nueva torre campanario de la

en la Valencia gótica de 1350 a 1480 . Aproximación a su estudio. (Tesis de licenciatura s. p.), Universitat de València, 1996, pp. 197-198.

25. PACEY, A.: op. cit., p. 117. Para el periodo posterior a 1360 poseemos mayores evidencias documentales respecto a siglos anteriores. Estas referencias se multiplican en el siglo xv, sobre todo a partir de contratos que apelaban a esos modelos que el constructor debía seguir según su acuerdo con el propietario.

26. Rubio SAmper, J.M.: «La figura del arquitecto en el período Gótico. Relaciones entre España y el resto de Europa», Boletín del Museo e Instituo Camón Aznar, 22 (1985), pp. 105-107.

27. Salzman, L. F.: Building in England down to 1540. Oxford, Clarendon Press, 1997, p. 16.

28. Archivo del Reino de Valencia (ARV), Batllia General, Lletres i Privilegis, 45, f. 292 r. El maestro invirtió tres meses en un viaje que costó 270 sueldos, que incluían el salario de las jornadas de ida y vuelta además de los propios gastos del desplazamiento. Citado por Sanchís Sivera, J.: op. cit., 1925, pp. 25-26, 42.

29. Montero, E.: op. cit., p. 222. La mostra ofrecía un referente visual al que remitirse en caso de duda o incumplimiento del contrato.

30. Amv, Notales de Antoni Pascual, p-2. Citado por Tramoyeres Blasco, L.: «Los artesonados en la antigua Casa municipal de Valencia. Notas para la historia de la escultura decorativa en España». Archivo de Arte Valenciano, 3 (1917), pp. 45-46.

31. Rubio SAmper, J.M.: op. cit., p. 106. Ejemplos célebres fueron los casos de maestros como Simone de Orsénigo tras su paso por la catedral de Milán, Mirtiz Enzinger en Ulm o Guillem Sagrera en Mallorca. 


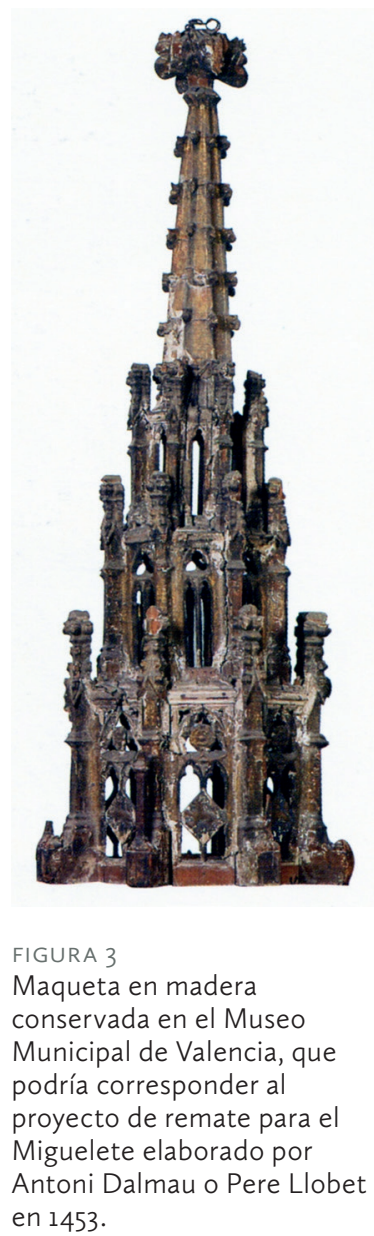

catedral de Valencia, ante el temor de que se extraviase ${ }^{32}$ (FIGURA 3). A pesar de este deseo de conservar el boceto, en la mayoría de los casos, una vez cumplida su función se perdía el interés y por tanto son escasos los ejemplares conservados. Su pervivencia en muchos casos es meramente accidental, como el célebre palimpsesto de Reims, que sobrevivió gracias a la reutilización del pergamino sobre el que estaba esbozado para la redacción de obituarios y ceremoniales ${ }^{33}$. Ante la pérdida de estas piezas, noticias documentales dispersas constatan su existencia e informan de la calidad tridimensional de modelos fabricados en madera o yeso, y de su importancia ejemplar. Como elemento portátil que tan pronto podía servir para presentar la traza al promotor como para enseñar a los maestros de obras, oficiales y aprendices el diseño a elaborar en el transcurso de la obra ${ }^{34}$.

La elaboración de techumbres en madera ofrecía otro campo de reciprocidad entre la arquitectura y la carpintería. Las llamadas «cubiertas de casas» contaban con una larga tradición en Valencia y, de hecho, era una actividad que las ordenanzas de la corporación de los carpinteros de I482 declaraban privativa del oficio. Tanto en los libros contables de fábrica como en los de la propia corporación, sus artífices no aparecen identificados como carpinteros de lo blanco o alarifes ${ }^{35}$, sino como carpinteros simplemente, a veces como imagineros, ymaginaires ${ }^{36}$. Se trataba de maestros constructores cuya especialidad profesional sólo es posible descubrir a través de la documentación, a partir de contratos notariales y libros de obra, que traslucen la naturaleza de su oficio al describir el objeto de la contratación y precisar su compromiso al aceptar el trabajo.

Esta ambigüedad de las fuentes al definir la vertiente laboral del carpintero, nos obliga a contrastar las noticias documentales para esclarecer la índole de sus actividades. Sólo así se localizan bajo el nomenclátor genérico de carpinterius a maestros constructores como Joan Perales y Guillem Gilabert, que fueron solicitados en I507 por la duquesa de Gandía María Enríquez para desmontar los alfarjes de los dos estudios del palacio de la familia Borja en Valencia y aprovechar el transcurso de las reformas del inmueble para llevar a cabo las reparaciones oportunas ${ }^{37}$.

32. Sanchís Sivera, J.: op. cit, pp. 98-100. Catalogado como «Fanal Morisco» se conserva en el Museo Municipal de Valencia una maqueta en madera que podría corresponder al proyecto de remate para el Miguelete elaborado por Antoni Dalmau o Pere Llobet.

33. Coldstream, N.: op. cit., 2002, p. 73.

34. Sobre la función del boceto, véase RUIZ DE LA ROSA, J.A.: «El arquitecto en la Edad Media», en GRACIANI, A. (ed.): La técnica de la arquitectura medieval. Sevilla, Universidad de Sevilla, 2001, p. 166.

35. Sobre la terminología empleada en la carpintería española, se recomienda el léxico recogido por NUERE MATAuco, E.: La carpintería de armar española. Madrid, Munilla-Lería, 2003, pp. 254-378.

36. ARV, Gremios, Libro 174 bis. Consta en los sucesivos libros de clavería reunidos en el cuadernillo de las cuentas entre 1434 y 1441.

37. ARV, Protocolos, Notario Joan García, 4.534. Comisión citada por Falomir Faus, M.: Arte en Valencia, 
En este sentido, los acuerdos para la construcción de techumbres de madera en el occidente europeo prevalecieron dos tipos de contratación ${ }^{38}$. En una primera modalidad, el comitente se dirigía al carpintero, quien elaboraba su propio diseño a conformidad del benefactor. Ésta fue la opción de los hermanos Guillem y Francesc Maestre al contratar a Bartomeu Pérez el I6 de setembre de I4I5 para que suministrase, labrase e instalase sesenta y seis vigas convenientemente «obradas y planeadas» para la obra que realizaban en el convento de framenores de Sagunt ${ }^{39}$. Una variante de esta forma de contrato fue el encargo a Joan del Poyo, como maestro la ciudad, de diseñar los alfarjes de la antigua Casa de la Ciudad, el de la sala dorada o Cambra Daurada (I4I8-I428, I44I y siguientes) y el de la sala del consejo, más conocida como Sala dels Àngels, entre I423 y I42840. La techumbre de la Cambra Daurada se emprendió a raíz de las reformas del edificio en el primer decenio del siglo xv. El proyecto se enmarcaba dentro de la política de prestigio de la ciudad orientada a la defensa de sus privilegios a raíz del cambio dinástico que llevó a la entronización de los Trastámara. De conservarse íntegramente, sería un buen ejemplo de esa voluntad de distinción tan manifiesta en las sesiones del consejo de aquellos años ${ }^{41}$. Con todo, a comienzos de 1423 un incendio en la sala del consejo obligó a interrumpir las obras de la sala dorada y renovar la techumbre de la que hasta entonces había servido como salón de reuniones. De nuevo los jurados confiaron el proyecto a Joan del Poyo, por su reputación al frente de las obras de la ciudad ${ }^{42}$. De hecho, al frente de estas obras, no sólo planteó las propuestas y dirigió al equipo de maestros carpinteros, albañiles y picapedreros que intervinieron, sino

1472-1522. València, Consell Valencià de Cultura, 1996, p. 193. El contrato para desmontar y colocar «las cubiertas de madera de los dos estudios de su palacio, esto es del de las coronas y el otro de las rosas» nacía de la voluntad de preservar las techumbres durante las reformas del palacio de la familia Borja situado en la parroquia de San Lorenzo de Valencia. El deseo expreso de trasladar las cubiertas a otras estancias del palacio y aprovechar esta circunstancia para efectuar las reparaciones oportunas denota la estima por las techumbres por parte de la sociedad coetánea.

38. ANDERSON, P.: «Francesco Nicolini, falegname et intagliatore in legno, and the Role of Carpenters in Cinquecento and in Seicento Rome», Pantheon: Internationale Jahreszeitschrift für Kunst, 57 (1999), pp. 91-92. Como muestra de estas tres posibilidades, presenta los ejemplos de la iglesia de Santa Susana en Roma en la que el carpintero Alessandro Castaldi construyó la techumbre a partir de los diseños de Carlo Maderno. La cubierta de San Juan de Letrán ilustra el caso del arquitecto o pintor que proporcionaba el esquema. En las decoraciones de Pompeo Veronese para el duque de Mantua, los carpinteros Flaminio Boulangier y Vico di Raffaelle de Lazzaro sometieron su proyecto a la aprobación del comitente en el concurso organizado para ofrecer al mejor precio los diseños más votados.

39. Webster, J.B.: Per Déu o per diners. Els mendicants i el clergat al País Valencià. Catarroja-Barcelona, Afers, 1998 , p. 55 .

40. Tramoyeres Blasco, L.: op. cit., pp. 31-71. El derribo del edificio en 1854 comportó la pérdida de ambas techumbres, salvo la de la «Cámara Dorada, que pudo ser recuperada. En un primer momento se depositó en el sótano del Palacio Arzobispal, donde permaneció mientras se prolongaban las disputas sobre la venta de la madera en el concejo municipal, siempre impedida por los partidarios de su conservación. Finalmente, a raíz de la restauración de la Lonja en 1892, se planteó la posibilidad de montarla de nuevo en alguna de sus dependencias, lo que promovió el inventario de las piezas antes de su ubicación en el Salón del Consolado del Mar donde se halla actualmente.

41. Serra, A.: «El fasto del palacio inacabado. La Casa de la Ciudad de Valencia en los siglos XIV y XV», en Alonso, E., MURAD, M. \& TABERner, F. (eds.): Historia de la ciudad: arquitectura y transformación urbana de la ciudad de Valencia. Valencia, Colegio Territorial de Arquitectos de Valencia, 2004, p. 87. Al ímpetu político de la oligarquía se sumaron intereses económicos y motivos de orgullo cívico, en el intento de potenciar la imagen de la capital frente a otras ciudades de la Corona.

42. Serra. A.: «Al servicio de la ciudad: Joan del Poyo y la práctica de la arquitectura en Valencia (1402-1439)», Ars Longa, 5 (1994), pp. 111-119. 
FIGURA 4

Techumbre de la Cambra Daurada de la antigua Casa de la Ciudad de Valencia, 1418-1428, 1441-1458. Valencia, Sala del Consolat del mar.

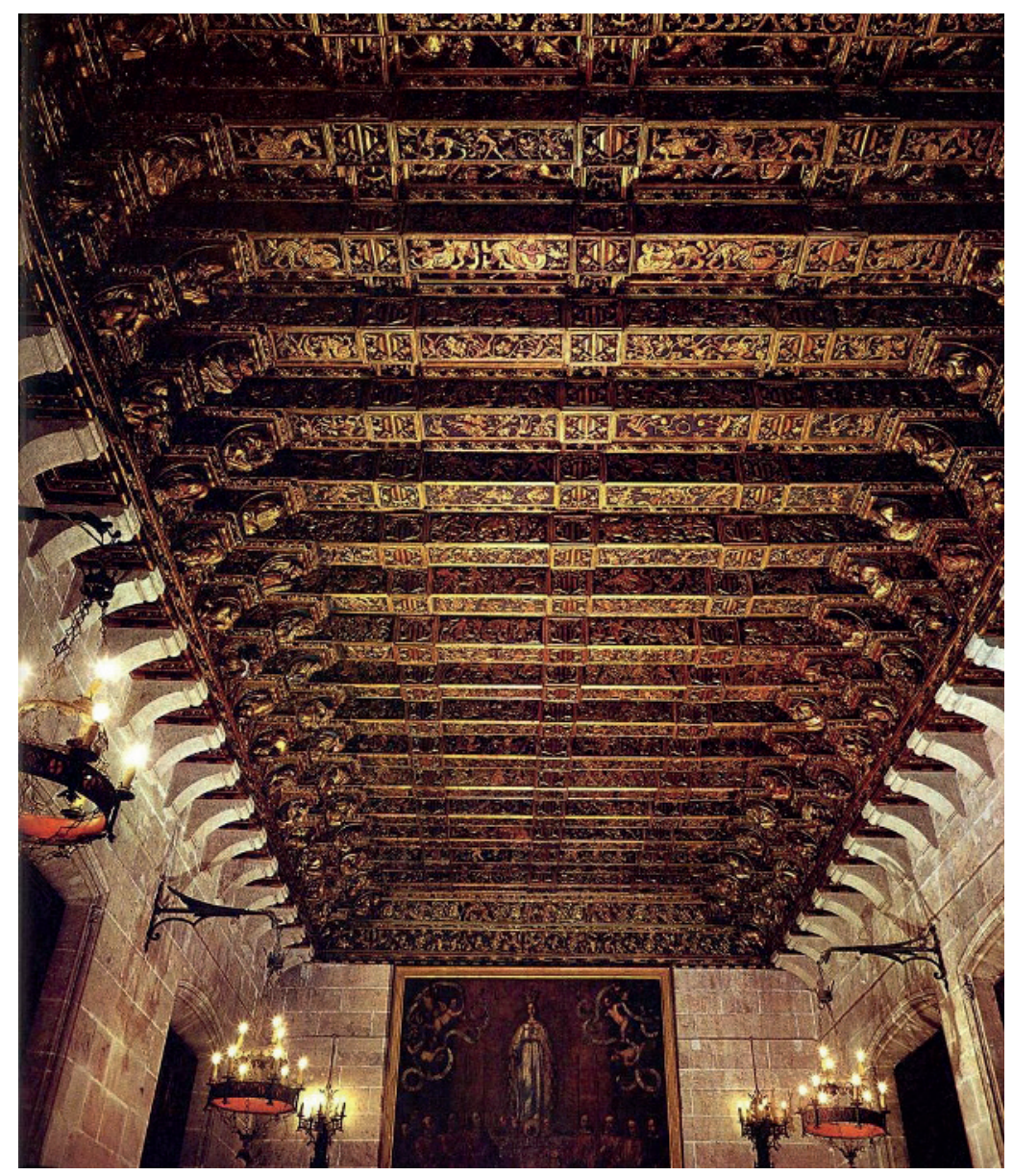

que actuó como un auténtico empresario, encargándose de la compra de materiales e incluso del transporte en sus propios $\operatorname{carros}^{43}$ (FIGURA 4).

En una segunda opción, el arquitecto, o incluso un pintor, facilitaba el diseño estructural dejando el trazado de los detalles ornamentales al carpintero. Un ejemplo de esta modalidad fue el acuerdo concertado el 20 de julio de I5I4 entre Joan Mançano, maestro de obras del Palacio de la Generalitat, y el escultor Lluís Monyos para la cubierta de la capilla. Según lo convenido, el carpintero asumía toda la responsabilidad de suministrar, preparar y labrar la madera, incluso aportar la mano de obra y los aparejos necesarios para llevar a cabo el proyecto. Joan Mançano recibiría los 7.00o sueldos valencianos del coste de la obra. De ellos le correspondían 500 sueldos por su intervención como albañil y contratista e intermediario, mientras que los 6.500 sueldos restantes debía entregarlos en tres plazos al carpintero ${ }^{44}$.

43. amv, Notal de Jaume Desplà, n-21. Citado por Tramoyeres Blasco, L.: op. cit., p. 50.

44. ARv, Generalitat, Protocolos de Pere Bataller, 2.736. Citado por AldanA, S.: El Palacio de la «Generalitat» de Valencia. València, Consell Valencià de Cultura, 1992, vol. I, p. 188. Lo menciona también Company, X.: L'art i els artistes al País Valencià modern (1440-1600). Comportaments socials. Barcelona, Curial, 1991, p. 199. 
Finalmente, un tercer punto de conexión lo plantearon las obras de ingeniería hidráulica, que emparejaban las competencias de los carpinteros con las de los maestros canteros. La primera referencia sobre la construcción de acequias y la conducción de agua a Valencia la proporciona Arnau Vidal, maestro de obras de la Catedral en I267, elegido en I273 como maestro de las obras de la Acequia Real de Alzira. En I362 Andreu Julià se presentaba a sí mismo como «maestro mayor de la obra de la catedral de Valencia y maestro experto en arte de nivelar» ${ }^{45}$. A tenor de esta connivencia entre la arquitectura y la ingeniería parece como si los conocimientos en cálculo y agrimensura bastasen para resolver problemas de hidráulica. El arte de nivelar no era en absoluto una actividad subestimada, a ella se dedicaron buenos maestros «poseedores de experiencia y conocimiento», expertos que solían recibir salarios que doblaban el jornal medio de canteros y albañiles y que, en base a su prestigio, eran frecuentemente llamados a consultas, lo que propició su movilidad y, con ella, la transferencia de conocimientos ${ }^{46}$.

Cuando en octubre de 1375 se planteó la posibilidad de realizar un trasvase del Júcar al Turia cerca de Tous, se requirió la opinión de maestros expertos «en el arte de la geometría» de Barcelona y Manresa, de Bernat Boix, albañil, y de Bernat Tosquella, carpintero, quienes se encargaron en febrero de 1376 de nivelar el terreno y calcular el coste de las obras ${ }^{47}$. En este punto cabe recuperar la figura de Joan del Poyo, «uno de los más aptos, singulares y famosos maestros en su arte u oficio en este Reino», que en I403 se desplazó con el carpintero Francesc Pina a Santa Cruz de Moya, a orillas del Turia, y a Salvacañete, a los pies del Cabriel, para estudiar un nuevo trasvase. Entre I4I6 y I4I7 revisó el sistema de regadío de Castellón con el maestro cantero Domingo Montpahó y a partir de 1420 se ocuparía aún de la construcción de molinos y norias, operaciones propias del maestro de hacha ${ }^{48}$. Es significativo observar que en las operaciones que realizó siempre iba acompañado por un equipo multidisciplinar de maestros carpinteros, canteros o albañiles, porque las operaciones no eran nunca competencia exclusiva de una sola especialidad.

45. ZarAgozÁ, A.: «Juegos matemáticos: aplicaciones geométricas de los maestros del gótico en el episodio valenciano», en YARZA, J. \& FITÉ, F. (eds.): L'artista-artesà medieval a la Corona d'Aragó. Lleida, Universitat de Lleida - Institut d'Estudis Ilerdencs, 1999, pp. 194-198. Los procedimientos técnicos y los sistemas empleados se pueden inferir de los textos legados por el coetáneo sienés Mariano di Jacopo (1382-1458), llamado /l Taccola, que sirvieron de referente a arquitectos como Francesco di Giorgio Martini o Leon Battista Aberti en su Ludi rerum mathematicarum. 46. Serra, A.: op. cit., 2012, p. 165.

47. AMv, Manual de Consells, A-17, ff. 20, 38 v - 39 v. Citado por GLICK, T.: Regadío y sociedad en la Valencia medieval. Valencia. València, Del Cènia al Segura, 1988, pp. 151-152. SerRA, A.: «Canales, acequias y puentes. Las actividades de los maestros de obras de la ciudad y el territorio de Valencia (siglos XIV y XV)», en DAUKSIS, S. \& TABERNER, F. (eds.): Historia de la ciudad. Territorio, sociedad y patrimonio: una visión arquitectónica de la historia de la ciudad de Valencia. Valencia, Colegio Territorial de Arquitectos de Valencia, 2002, pp. 165-166.

48. Serra, A.: op. cit., 2002, pp. 108-124. Se recomienda ZaragozÁ, A. \& Gómez-Ferrer, M.: Pere Compte, arquitecto. València: Generalitat Valenciana, Centro UNESCO, 2007, p. 179. 


\section{MAESTRO DE OBRAS DE CARPINTERÍA Y MAESTRO DE OBRAS DE LA CIUDAD: LA DUPLICACIÓN DE UN CARGO MUNICIPAL}

La figura de Joan del Poyo es quizá el ejemplo más ilustrativo de esta correspondencia entre el carpintero y el maestro de obra, documentado en Valencia desde 1393 como «mozo del maestro» en el equipo dirigido por Domingo Beneyto en el portal de Serranos, el joven Joanet del Poyo se revelaría con el tiempo como un artista polifacético ${ }^{49}$. Miembro de la corporación de carpinteros, revelador fue su nombramiento como maestro mayor de la ciudad en calidad de carpintero, ingeniero civil y militar y maestro constructor al comparecer en la sesión del consejo del I4 de marzo de I4I8 para solicitar un reconocimiento más justo a sus responsabilidades, por las que recibía tan sólo el jornal raso el día que trabajaba ${ }^{50}$. En estima de su capacidad laboral, el 3I de marzo los jurados acordaron satisfacer sus demandas y retribuirle en adelante 50 florines de oro aragoneses al año, con carácter retroactivo, y la promesa de "grandes ventajas, aparte de su ordinario y cotidiano salario» ${ }^{5}$.

A nivel profesional, el elenco de las obras que realizó descubre la duplicidad característica de la arquitectura medieval, en la que la madera resultaba imprescindible. La amplitud de sus habilidades le brindó la oportunidad de implicarse en encargos diversos, en una trayectoria en la que arquitectura, carpintería e ingeniería iban de la mano, perfectamente integradas en el concepto multidisciplinar de un maestro que se involucró en cada una de las operaciones de la construcción, hasta desmarcarse como arquitecto. Su desaparición en I 438 aconsejó a los Jurados de Valencia la parcelación de las responsabilidades asumidas hasta entonces por un único maestro, para encargar las operaciones de albañilería a un experto del arte, y los trabajos en madera a un carpintero ${ }^{52}$. Así, en julio de 1439 el Consejo decidía la creación del oficio de maestro de la obra de carpintería, cargo que puso de manifiesto el alcance de la presencia de este sector en la construcción. El maestro elegido debía encargarse de las comisiones puntuales consignadas por el gobierno municipal, su salario se ceñía al jornal corriente el día de trabajo, «sin que no pueda haber ni haya salario ni gracia alguna de la ciudad, sino sus jornales». Claro está, a la garantía de contar con un empleo estable con el que afianzar la hacienda familiar, se añadían el prestigio y las ventajosas posibilidades de aumentar su clientela. El

49. AMV, Sotsobreria de Murs e Valls, $d^{3}-5, f .130$ v.

50. amv, Manual de Consells, A-26, f. 312. Citado por Tramoyeres, L.: op. cit., pp. 68-69. Aludido por Serra, A.: «Al servicio de la ciudad: Joan del Poyo y la práctica de la arquitectura en Valencia (1402-1439)», Ars Longa, 5 (1994), pp. 113-114.

51. amv, Manual de Consells, A-27, años 1418-1425. Citado por Tramoyeres, L.: op. cit., pp. 68-69. Serra, A.: op. cit., 1994, pp. 113-114.

52. Serra, A.: op. cit., 1999, pp. 409-410. Joan del Poyo trabajó para la ciudad desde 1402, siendo responsable de obras reforma, tasaciones, intervenciones urbanísticas, de ingeniería hidráulica y carpintería, así como de la construcción de distintos tipos de máquinas. Después de un lapso de diez años, entre 1407 y 1417, comparece de nuevo en la documentación pero ya con un prestigio afianzado sobre su polifacética capacidad de trabajo. Consta en las obras de renovación de la Casa de la Ciudad y, en su calidad de maestro de obras de la urbe entre 1418 y 1439 participa en todas las empresas municipales, sin que sea posible adjudicarle una en exclusiva, siendo difícil mencionar un proyecto de relieve en el que no estuviese implicado. 
cargo del maestro de la ciudad se desdobló al reestructurar el contrato, para ajustar las responsabilidades a las cualificaciones profesionales de cada sector. Emergían así en el oficio municipal el maestro de obras y el maestro carpintero, sujetos ambos a las mismas condiciones laborales, remodelación que permitió recalificar a la baja las compensaciones económicas de los artífices y reducir así los costes de las reformas urbanísticas ${ }^{53}$.

Su creación manifiesta la impronta de la construcción en el espacio físico, y económico de la urbe, enmarcada en un proceso paulatino de especialización técnica de ambos oficios que no escapó a la comprensión de las autoridades. El i de julio de I439 se aprobaba la elección de Pere Vecho como relojero, Francesc Torçà como «maestro de obra de la ciudad» y Miquel Joan «del trabajo de la obra de madera» desprovistos ya de los privilegios de su predecesor ${ }^{54}$. Un año después de su nombramiento, Francesc Torçà sería sustituido por Jaume Gallent, quien mostró un perfil ceñido a los propósitos de albañilería que infería el cargo. Aún así, en I44I elaboró para el Real el modelo tridimensional de la nueva torre que coronaría la Cámara de los Ángeles, muestra de su capacidad como maestro constructor y su familiaridad con los rudimentos técnicos de la carpintería, lógicos por los vínculos que unían ambas disciplinas ${ }^{55}$. Al servicio del municipio se mostró un maestro solvente, en ingeniería hidráulica intervino en la construcción de la nueva acequia del marjal en I444. En I453 Andreu Valero lo reemplazaría en el cargo, documentado en las obras del portal de Quart, en el puente del Mar y en la reparación de murallas. No fueron cargos de larga duración, tras el nombramiento de Guillem Bonfill en I453 en substitución de Andreu Valero, y la promoción de Jaume Llombart el 28 de agosto de I457 en sustitución de Miquel Joan, el oficio parece extinguirse, ya que en adelante los «Manuals de Consells» no contienen ninguna noticia sobre la investidura de nuevos maestros que cercioren la continuidad de estas atribuciones.

El maestro carpintero se encargaba de supervisar el estado de los puentes de madera, de encargar las intervenciones a un grupo de operarios cualificados, de controlar la compra de los materiales y revisar los costes. Era responsable de garantizar la correcta ejecución y la legalidad de las operaciones en cada obra. Un empeño esencial de su tarea eran los preparativos para las entradas reales, en las que era requerido para montar tarimas, decorar los principales edificios de la ciudad, distribuir luminarias por las torres y las calles comprendidas en el recorrido de la comitiva. Estas operaciones incluían también a otros colegas de oficio que, en ocasiones festivas, veían sustancialmente incrementadas sus perspectivas de trabajo. Era un artífice polifacético, ejercitado en diversas modalidades de la profesión,

53. AMv, Manual de Consells, A-32, f. 104 r.

54. amv, Manual de Consells, A-32, f. 104 r. Citado por Serra, A.: op. cit., 1994, p. 118. El nombramiento coincidía con la designación del albañil Guillem Bonfill y el carpintero Joan Granada como delegados de la corporación de carpinteros en el gobierno municipal, noticia referida en AMv. Manual de Consells, A-32, f. 76 r.

55. Serra, A.: op. cit., 1999, p. 413. El encargo de la maqueta lo mencionaba ya SANChís SiverA, J.: op. cit., 1925, p. 42. El registro lo transcribió íntegramente SÁNCHEZ, M.: El maestro de obras o la práctica de la arquitectura en la Valencia gótica de 1350 a 1480. Aproximación a su estudio. (Tesis de licenciatura, s. p.), Universidad de Valencia., 1996, pp. 197-198. 
capaz de actuar como ingeniero, arquitecto, escenógrafo o empresario proveedor de materiales de construcción ${ }^{56}$.

La renovación del perfil del maestro de la ciudad descubre la estrecha colaboración entre ambos oficios y justifica que en este período estuviesen englobados en un mismo colectivo profesional. A ellos incumbía la inspección del trazado urbano, la tasación de las obras a realizar en caso de reformas encargadas invariablemente a un albañil y un carpintero por la Fábrica de Muros y Valladares. Esta institución, implantada en Valencia en I358, encontraba su paralelo en ciudades como Londres a través de la Office of City Viewers, documentada desde I27I, que estaba integrada por carpinteros y albañiles responsables de examinar las murallas, los puentes y el alcantarillado de la ciudad ${ }^{57}$. Desde esta perspectiva, aparece lógica la inclusión de la albañilería en la disciplina de la carpintería, en Valencia convenientemente incluida en el listado de los brazos del oficio proporcionado por los estatutos de I424. Constituye la primera referencia a las especialidades de la corporación, sin embargo corresponde ya a un período en el que el colectivo de albañiles contaba ya con unas bases institucionales relativamente sólidas, que marcarían su alejamiento progresivo y la separación de las competencias técnicas de ambos oficios. La documentación suscribe en estos decenios centrales del siglo xv una convivencia inestable, trabada de dificultades, en la que el colectivo de los albañiles se mostró como uno de los grupos más activos al reivindicar su autonomía.

\section{LA FUNDACIÓN DE UNA CORPORACIÓN AUTÓNOMA DE MAESTROS DE OBRA}

Los proyectos urbanísticos emprendidos desde la primera década del Cuatrocientos beneficiaron en general a todos los oficios de la construcción. Conscientes de la necesidad de regular un oficio en auge, los maestros de obras emprendieron desde comienzos del siglo xv las primeras iniciativas de emancipación. A este propósito respondía la credencial de Fernando i de Antequera el i8 de mayo de I4I5 que autorizaba a los albañiles a fundar una cofradía propia, que ocuparía el puesto veintisiete en el Consejo General de Valencia ${ }^{58}$. Un frontispicio miniado en el verso del primer folio inaugura la compilación, con la imagen de la Crucifixión con

56. Munby, J.: «Wood», en BlaIR, J. \& RAmSAY, N. (eds.): English medieval industries: craftsmen, techniques, products. London, Hambledon and London, 2001, p. 387. La multiplicidad de las operaciones encomendadas al maestro carpintero en Valencia es parangonable a la del maestro Thomas de Houghton al entrar al servicio del rey como carpintero e ingeniero entre 1288 y 1318.

57. Addison, M.: «The naked and the dead: the Carpenters' company and lay spirituality in late medieval England», en Robertson, K. \& Uebel, M. (eds.): Middle Ages at work, practicing labor in late medieval England. New York, Palgrave Macmillan, 2004, p. 95.

58. AMv, Caja 14, número 15. El privilegio inicia la compilación estatuaria comprendida en un códice conservado en el Archivo Municipal de Valencia que, bajo el título de «Capítulos y Ordenanzas acordadas entre los maestros albañiles», reúne las disposiciones aprobadas por el oficio hasta 1660. Como evidencia la variedad de su caligrafía, el volumen se compone de legajos de períodos sucesivos, englobados en una cuidada edición en vitela y encuadernada en piel, con aplicaciones metálicas en la tapa para proteger los bordes. Citado por IzQUIERdo ARANDA, T.: op. cit., 2014, pp. 140-142. 
la Virgen y San Juan a los pies de la cruz enmarcada por una filigrana con los símbolos del tetramorfo. El recto del segundo folio contiene la provisión del monarca en respuesta a la «suplicación» elevada «por parte de algunos maestros de casas y otros singulares ciudadanos de la ciudad de Valencia que usan del oficio de obra de villa»59. Recoge a continuación la aprobación de Alfonso $v$ sin que entre ambas disposiciones medie ninguna disposición estatuaria ${ }^{60}$. Sólo después aparece una breve relación de previsiones de solidaridad y aspectos litúrgicos, cuyo contenido recuerda el carácter de las primitivas disposiciones de la cofradía de carpinteros. Las imprecisiones y la cautela con la que se expresan denotan más bien proyectos de futuro. Revelan el carácter de tentativa de constituir una sociedad autónoma que otorgase mayor jurisdicción laboral e institucional al albañil.

Puesto que los estatutos de la corporación de carpinteros de I424 los sitúan perfectamente encuadrados en el primer tercio de siglo, al interpretar esta licencia real es fácil asumir que no redundaría en la fundación de una entidad autónoma, sino que más bien formalizaría una especie de capitulado para establecer las bases de regimiento interno de un colectivo que sólo a partir de I442 iniciaría una auténtica dinámica normalizadora. Resulta oportuno recalar en la estructura del códice, porque el orden y la cronología de los textos delatan la trayectoria del oficio, desde los primeros tanteos de autonomía hasta su completa emancipación. Los privilegios reales inauguran la resolución y ocupan los catorce primeros folios, en los cinco siguientes se emplazan previsiones asistenciales preliminares. Sólo en mayo de I442 se incorporarían en dos folios unas breves orientaciones directrices que quedarían suspendidas hasta I49I, momento en que se emprendió la aprobación de estatutos caracterizados por una decidida vocación reglamentaria.

En este punto, resulta ilustrativo contrastar los datos aportados por el códice con los registros de los consejos municipales en el cuarto decenio del siglo xv, ya que en la década de los años treinta la delegación de carpinteros al consejo de la ciudad figuraba bajo el apelativo unívoco de «carpinteros», independientemente de su especialidad, mientras que entre I 438 y I446 los representantes del oficio se inscribían bajo la rúbrica categórica de «carpinteros y albañiles», para matizar la rama a la que pertenecía cada delegado ${ }^{61}$. Así, hasta 1442 la documentación el albañil aparece perfectamente acomodado en el seno de una sociedad en la que debió de gozar de una notable presencia, patente en estas comisiones al gobierno municipal donde compartían un grado análogo de representación política ${ }^{62}$. Sólo en I447 desaparecerían los representantes de los maestros de obra, para comparecer dos años más tarde enrolados en una delegación propia que proyecta en primicia los orígenes de su incipiente corporación.

\footnotetext{
59. AMv, Caja 14, número 15, ff. 2-13 v.

6o. AMv, Caja 14, número 15, f. 14 r.

61. AMv, Manual de Consells, A-32, f. 6 v. Elegido el albañil Francesc Torçà junto al carpintero Miquel Joan, es significativo remarcar que mientras el primero desaparece en los años siguientes de la delegación en el gobierno municipal, el delegado de los carpinteros conserva su plaza como representante del oficio.

62. Amv, Manual de Consells, A-30, f. 174 v. Citado por Falomir, M.: op. cit., pp. 195. Ejemplo de la comisión del 28 de mayo de 1434 en que fueron elegidos Pasqual Esteve, carpintero y Vicent Navarro, albañil. Sobre el estatus del albañil se recomienda consultar las noticias recogidas por el autor en el capítulo en que contempla este sector.
} 
El proceso continuo de vaivenes manifiesta las tensas gestiones suscitadas, tras las cuales se intuyen las aspiraciones latentes del sector. Se desconocen los detalles de su escisión, los motivos fáciles de imaginar, concernientes a una mayor independencia laboral y al deseo de regir libremente un oficio en auge. Bajo estas premisas, su emancipación parece el final de un largo período de tensiones internas para el que resultaría inabordable fijar una fecha exacta. Con todo, el golpe de gracia sería el incremento que experimentó la edificación de viviendas en el último cuarto de siglo, en especial entre 1489 y I500, cuando se erigieron más de un millar de casas particulares en Valencia ${ }^{63}$. En espera del documento que aporte más noticias, todo parece indicar que el florecimiento en la construcción proveyó al colectivo la confianza y el respaldo económico necesarios para sostener sus reivindicaciones ${ }^{64}$. Así, en I49I los albañiles emprendieron una activa política de regulación iniciada con la ampliación estatutaria, en agosto de 1496 obtuvieron permiso para establecer un examen como medida de control de acceso al magisterio. Consistía en un ejercicio teórico en la que el candidato probaba su dominio de las artes del diseño, seguido de la elaboración de una pieza maestra con la que mostraba su pericia en el dibujo. La prueba ponía de relieve la importancia del conocimiento del vocabulario arquitectónico y de las leyes de la geometría para ejercer la profesión ${ }^{65}$. En este sentido, pese al decreto otorgado por Fernando de Antequera en I4I5, sólo tras obtener plena libertad tomaría forma la institución, sólo entonces las ordenanzas se convirtieron en auténticos estatutos corporativos, coincidiendo con el momento en que los jurados municipales emprendían las primeras iniciativas para regular el sector, conscientes de la potencialidad y la incidencia de la construcción en la economía urbana ${ }^{66}$.

63. Villalmanzo, J.: «Estudio histórico sobre el gremio de carpinteros de Valencia», en Villalmanzo, J. \& PÉrez, D. (eds.): Llibre de Ordinacions de la Almoyna e Confraria del Offiçi dels Fusters. València, Javier Boronat, 1990, pp. 34-35. SerRA, A.: «Orden y decorum en el urbanismo valenciano de los siglos XIV y XV», en CASAMENTO, A. \& GUIDONI, E. (eds.): Le città medievali dell'Italia meridionale e insulare. Roma, Edizioni Kappa, 2002, pp. 37-50. Recapitula en una reflexión panorámica los motivos de la política arquitectónica emprendida por el Consejo como responsable de las decisiones sobre urbanismo dentro del marco jurídico de los fueros y privilegios tratando de individualizar las razones ideológicas que promovieron estas intervenciones.

64. YARZA, J.: «L'Artista-artesà medieval a la Corona d'Aragó», en YARZA, J \& FITÉ, F. (eds.): L'artista-artesà medieval a la Corona d'Aragó. Lleida, Universitat de Lleida - Institut d’Estudis Ilerdencs, 1999, p. 39. El historiador subraya el hecho de que los sectores con un colectivo menos numeroso, al carecer de la potencialidad necesaria para fundar una propia, se unían al entorno de grupos productivos afines para obtener una protección institucional y mutualista para hacer frente a posibles imprevistos.

65. Amv, Manual de Consells, A-48, f. 372.

66. IzQuierdo Aranda, T.: op. cit., 2014, p. 143. En este último decenio del siglo aprobaron una batería de medidas de carácter marcadamente laboral, con precisiones técnicas relativas a los métodos de producción y a los criterios para la contratación con la intención de controlar el mercado laboral. No sólo la construcción unía al albañil y al carpintero, los conflictos tras obtener la autonomía profesional descubren actividades comunes como marcar piezas de madera, operaciones hasta entonces privativas de la carpintería, cuya exclusiva no les sería fácil de conseguir; trece años se prolongaría un sumario resuelto finalmente a favor de los carpinteros. Por su parte, los capítulos fueron ampliados y modificados en julio de 1500, en mayo de 1517, en junio y agosto de 1563, en septiembre de 1612 y nuevamente en mayo de 1638 hasta que en septiembre de 1660 concluyeron la relación. 


\section{MAESTRO CARPINTERO Y MAESTRO CONSTRUCTOR}

La creciente complejidad de la arquitectura gótica, con unos diseños cada vez más sofisticados, impulsó el interés por el cálculo de los empujes y la resistencia. Carpintero, picapedrero o albañil, el maestro constructor responsable del proyecto edilicio debía ajustar la totalidad de los detalles de la construcción a partir de fórmulas precisas, aunque el aprendizaje práctico y el bagaje técnico acumulado por el oficio continuasen estableciendo las pautas de la transmisión de los conocimientos $^{67}$. El maestro de obra que concebía el proyecto era también el encargado de dirigirlo, aunque esta responsabilidad no implicase su reconocimiento como arquitecto, al menos en el sentido moderno de la palabra. En la Baja Edad Media el maestro constructor era fundamentalmente un artista hábil y polivalente, el operario más instruido, aquel que dominaba una serie de competencias particulares podía ser elegido como constructor en una obra y trabajar en otra como un simple obrero ${ }^{68}$. En este sentido, la formación práctica y empírica, basada en nociones geométricas y en la experiencia en diversas fábricas, constituían los factores determinantes ${ }^{69}$. Fue así como la destreza en el diseño y los principios de la geometría dotarían a los maestros carpinteros de las bases intelectuales oportunas para alcanzar la categoría de arquitecto. En un edificio, la estructura y las proporciones eran elementos determinados mediante un proceso hoy conocido como geometría constructiva, ya empleada por el arquitecto medieval que con sus instrumentos de trazado establecía las dimensiones a partir de figuras geométricas ${ }^{70}$ (FIGURA 5).

La llegada de la geometría euclidiana al occidente europeo se ha atribuido a la primera traducción al árabe del texto griego de Abelardo de Bath en torno a Iızo.

67. Solís Burgos J.A.: «La economía de la construcción en la Edad Media», en Graciani, A. (ed.): La técnica de la arquitectura en la antigüedad. Sevilla, Universidad de Sevilla, 1999, pp. 156-165. En la Edad Media la geometría adquirió un desarrollo inusitado en manos del artífice, se aplicó de manera generalizada tanto en la arquitectura como en los demás manifestaciones artísticas.

68. Rubio SAmper, J.M.: op. cit., 1985, p. 102.

69. Carraz, D.: L'architecture médiévale en Occident. Paris, Presses Universitaires de France, 1999, p. 43.

70. El planteamiento se desarrollaba a partir de una progresión geométrica basada en una serie de figuras básicas que funcionaban como una suerte de módulo para establecer las proporciones del edificio. Sobre el proceder en el proyección arquitectónica véase, Kostoff, S.: «El arquitecto en la Edad Media, en Oriente y Occidente», en Kostoff, S. (coord.): El arquitecto: Historia de una profesión. Madrid, Cátedra, 1984, pp. 88-90. Más recientemente considera la importancia de la geometría y el acceso a ella del arquitecto medieval ZENNER, M.T.: «Architectural Layout: Design, Structure, and Construction in Northern Europe», en RudoLPH, C. (ed.): A companion to Medieval Art. Oxford, 2006, pp. 535-541. 
A esta obra se sumarían las noticias y contactos directos con maestros sarracenos resultados de cruzadas y peregrinajes ${ }^{71}$. Desde mediados del siglo xil, manuscritos como Hortus Deliciorum de la abadesa Herrada de Landsberg o De Ortu Scientiarum del arzobispo de Canterbury Robert Kilwardby reconocían alegóricamente su impronta $^{72}$. La figura del maestro constructor con sus instrumentos de medición se convirtió en una de las representaciones predilectas para explicar la acción creadora de Dios, el arquitecto supremo efigiado con el compás en actitud de trazar el diseño del Universo. Al fin y al cabo, no era la arquitectura como disciplina la que era depreciada sino la práctica de la arquitectura por el trabajo manual que comportaba. Conforme penetraron en la Península los nuevos incentivos estilísticos procedentes de Italia o del Norte de Europa, el dominio de la geometría y el conocimiento de las leyes de la perspectiva capacitaron al maestro constructor como arquitecto.

El dibujo y la pericia para plantear y dirigir proyectos constructivos ennoblecieron a los maestros de obra. Con la profesionalización de su cargo se produjo un cambio significativo en su estatus, porque el arquitecto no era en definitiva más que un maestro capacitado con destrezas extraordinarias a su condición de menestral. La concepción del edificio precisaba de la intervención de especialistas, que se liberaron poco a poco del trabajo manual para convertirse en sabios responsables de concebir la obra y dar las órdenes oportunas ${ }^{73}$. En el ejercicio del trabajo cotidiano del carpintero medieval era manifiesta su formación en dibujo y perspectiva. Como escultor y constructor, constituían herramientas de trabajo indispensables, que adquiría en el aprendizaje del oficio y asimilaba con la experiencia continuada en la obra ${ }^{74}$. El dibujo se convirtió así en la vía de entrada de las artes del diseño, que penetraron en Valencia a mediados del Cuatrocientos para consolidarse en los siglos xv y xvi. A medida que se fortalecieron las relaciones comerciales con los principales puertos italianos y los contactos se hicieron más fluidos, se intensificaron los viajes de artistas que aportaron la mayor parte de las novedades estilísticas del Renacimiento 75 .

El conocimiento de la perspectiva fue vital en la instrucción del arquitecto, era esencial el dominio de la geometría y el dibujo para un artista constructor que debía basar su actividad en la delineación. Esta circunstancia fue decisiva para la entrada

71. Harvey, J.: The Medieval Architect. London, Wayland Publishers, 1972, p. 94. Al considerar la llegada de la geometría a Europea cabe tener presente que la geometría constructiva no era una invención medieval, la estrecha relación entre la arquitectura y la geometría había sido definida desde la Antigüedad por filósofos y matemáticos. En los sistemas medievales de proporciones, se tomaba en cuenta la geometría, el álgebra y la aritmética estaban presentes pero es difícil establecer hasta qué punto derivaban de un cálculo matemático consciente por parte de los maestros constructores.

72. Terrenoire, M.O.: Le travail d'architecture au temps des cathédrales. Dijon-Quetigny, Éditions Recherches, 2004, p. 69.

73. CarraZ, D.: op. cit., 1999, pp. 84-85.

74. ZaRAgOzÁ, A.: «El control de la forma en la arquitectura medieval valenciana: dibujo y oficios artísticos durante los siglos XIII y XIV», en Historia de la ciudad. vI. Proyecto y complejidad. Colegio Territorial de Arquitectos de Valencia, Valencia, 2010, pp. 82-83.

75. En este intercambio bilateral que revolucionaría la pintura valenciana en el Quinientos, no sólo pintores como Francesco Pagano, Riccardo Quartararo o Paolo de San Leocadio se desplazaron a Valencia, a la inversa se verificó también el viaje de artistas coterráneos a tierras italianas. Célebre es el ejemplo de Hernando de los Llanos y Hernando Yánez de la Almedina, procedentes del entorno de Leonardo da Vinci, que se instalaron en Valencia en 1506 una vez asimilada la técnica y el vocabulario del maestro florentino. 
del carpintero en la órbita del diseño arquitectónico, ya que en la obra su trabajo se basaba en el cálculo matemático y la geometría.

Desde esta perspectiva, el biógrafo toscano Giorgio Vasari reconocía al diseño en sus Vidas como el padre de la arquitectura, la escultura y la pintura, al concebirlo como un juicio universal que procedía del intelecto, y reivindicaba precisamente la figura del carpintero en la definición del perfil profesional del arquitecto ${ }^{76}$. En cambio, lamentaba la ignorancia de los artífices privados de comprensión de la perspectiva que, aferrados a los principios elementales del dibujo, desdeñaban la geometría y centraban el aprendizaje en la experiencia práctica ${ }^{77}$. Vasari estaba convencido de que el carpintero había accedido a la arquitectura gracias al diligente estudio de los elementos constructivos, al beneficiarse así de una formación en entalladura que requería aprender a dimensionar elementos estructurales y decorativos en términos de espacio y proporción, a valorar las medidas tomadas entre ellos y en relación a la totalidad de la composición, se tratase de edificios, muebles, retablos o monumentos $^{78}$. Un análisis del rol del artífice en los siglos xıv y xv muestra cómo a partir de estos rudimentos y en base a su experiencia en la obra era capaz de negociar de manera independiente sus contratos, de afrontar una gran diversidad de encargos artísticos e incluso rebasar los márgenes de su calidad de carpintero y ejercer como arquitecto.

En este sentido, es oportuno remontarse a la glosa añadida al Dictionarius de Joan de Garlandia en I220 precisaba «el Arquitecto es maestro carpintero», una apreciación advertida también en el Didascalicon de Hugo de San Víctor al definir la arquitectura como un arte dividido en dos destrezas: «El arte de la Arquitectura se divide en albañilería, que corresponde a picapedreros y albañiles, y en carpintería, que pertenece a carpinteros y ebanistas». Esta afirmación parece válida al confrontarla con calificaciones como la que reconocía el monje de la Catedral de Canterbury Gervasio al maestro constructor Guillermo de Sens, «en madera y piedra artífice subtilísimo» ${ }^{79}$. La documentación corrobora estas impresiones al mostrar al maestro constructor avezado en prácticas muy diversas y siempre implicado personalmente con el trabajo. Sus responsabilidades al frente de una obra no se limitaban al esbozo del plano constructivo o a la dirección de los trabajos, debía

76. La perspectiva revolucionaría las posibilidades técnicas de la carpintería medieval, la introducción del diseño comportó un nuevo vocabulario estilístico y una forma inédita de concebir el trabajo. Las aportaciones de la carpintería a estos cambios fueron apreciadas por el pintor e historiador Giorgio Vasari en la su obra bibliográfica. Las recomendaciones del artista toscano han sido destacadas en numerosos estudios sobre el arte de la ebanistería y la arquitectura. En el panorama europeo esta línea de formación se constata de la mano de autores como Giuliano y Antonio da Sangallo, Giovanni Battista Montano o Giovanni Battista Soria. Véase Anderson, P.: op cit., p. 98. COMANDuCCI, R.M.: «Buono artista della sua arte. Il concetto di artista e la pratica di lavoro nella bottega quattrocentesca», en FranceschI, F. \& Fossi, G. (eds.): La grande storia dell'Artigianato. I/ Quattrocento. Firenze, Giunti, 1999, voll. II, pp. 149-151.

77. VASARI, G.: Le Vite. Firenze, Sansoni Editore, 1550, p. 111.

78. Siguen siendo la referencia clásica en este campo SHELBY, L.R.: «The Education of Medieval English Master Masons», Medieval Studies, 32 (1970), pp. 1-26 y «The geometrical knowledge of medieval master masons», Speculum, 47 (1972), pp. 395-421, pero han sido sometidos a críticas recientes por visiones que reconsideran la relación entre la geometría de los constructores y la tradición clásica de Euclides, como ZENNER, M.T.: «lmaging a Building: Latin Euclid and Practical Geometry», en ContrenI, J.J. (ed.): Word, Image, Number: Communication in the Middle Ages, Florencia, 2002, pp. 219-246.

79. ReCHT, R.: Le dessin d'architecture: origine et fonctions. Paris, Adam Biro, 1995, p. 47. 
supervisar el abastecimiento de material, verificar su calidad, organizar las labores de extracción en la cantera, suministrar madera, arena y yeso. Así lo evidencian ejemplos como Domingo Beneyto, maestro de la obra de albañilería y carpintería en el portal de Serranos. Desde sus inicios en 1393 se encargó de suministrar tapiales, arena y yeso para la construcción de la «casa dels motles», la logia para la talla de la piedra instalada a pie de obra ${ }^{80}$. En mayo de 1395 se desplazó junto a Pere Balaguer hasta el pedregal de El Almaguer en Alginet para comprobar la calidad de la piedra y supervisar las tareas de extracción, compartiendo con el maestro picapedrero la responsabilidad de controlar el abastecimiento de materiales ${ }^{81}$. Por ello, de nuevo en marzo de 1397 verificaba la llegada de las primeras provisiones de piedra procedentes de la cantera Bellaguarda en Altea ${ }^{82}$. En el transcurso de las labores diarias, subcontrataba a su propio equipo de carpinteros, entre ellos sus aprendices Diaguet y Joan del Poyo, quien se formaría a su lado hasta convertirse en maestro de obras de la ciudad ${ }^{8}$. Responsable del correcto desarrollo de los trabajos, proporcionaba herramientas para el asserrado de la madera, limas para asegurar su puesta a punto.

Un ejemplo similar lo hallamos en el carpintero Joan Amorós al frente de las obras de la catedral de Valencia, de la que se encargaba del mantenimiento del edificio, de la planificación y elaboración de las intervenciones oportunas. Como maestro carpintero, tramitaba la compra de madera en la almoneda y se encargaba de la venta de las viejas maderas de la catedral, incluso en noviembre de I435 acompañó al síndico hasta Llombai y Cotes a buscar madera de carrasca para el campanario ${ }^{84}$. Por su parte, el albañil Jaume Gallent excediendo las actividades propias de su oficio, en marzo de I449 proporcionaba madera y sierras para la confección de los ventanales de la cárcel común en un claro encuentro entre las competencias de los carpinteros y los albañiles ${ }^{85}$. El maestro constructor actuaba en definitiva como un emprendedor que sumaba a sus conocimientos la experiencia práctica en la industria de la construcción. La multiplicidad de las funciones desempeñadas les llevaría incluso a ocuparse de la gestión de diversos proyectos de manera simultánea, a los que acudía periódicamente para supervisar las operaciones. Ejercían entonces una función directriz bien captada por predicadores como el dominico Nicolás de Biard o Santo Tomas de Aquino, que destacaban entre las habilidades que definían al arquitecto un saber hacer global de ciertas disciplinas complementarias, todas vinculadas a un mismo principio generador ${ }^{86}$. Reconocían por tanto una división interna en la práctica de la arquitectura, en la que el dominio de ciertas especialidades comportaba y abarcaba a las demás. Este conocimiento general

\footnotetext{
80. AMV, Sotobreria de Murs i Valls, $d^{3}-3$, f. 20 r.

81. AMV, Sotobreria de Murs i Valls, $d^{3}-5$, f. 8 r.

82. AMV, Sotobreria de Murs i Valls, $d^{3}-9$, f. 338 r.

83. AMV, Sotobreria de Murs i Valls, $d^{3}-5$, f. 124 r.

84. Archivo de la Catedral de Valencia (ACV), Libros de fábrica de la Catedral, 1.479, f. 50 v. Citado por IzQUIERDO ARANDA, T.: op. cit., 2014, pp. 272-273.

85. AMV, Sotsobreria de Murs i Valls, $d^{3}-51$, f. 10 r.

86. El reflejo de las prácticas arquitectónicas y de los oficios de la construcción en las predicaciones ha sido ampliamente estudiado, Roland Recht y Nicola Coldstream sintetizan los ejemplos más destacados. Véase RECHT, R.: op. cit., p. 45. Coldstream, N.: op. cit., p. 97.
} 
distinguía al arquitecto, que poco a poco se desligaría del trabajo manual para centrarse en la gestión de las operaciones, lo que le consentiría trabajar en varios proyectos al mismo tiempo.

En la construcción valenciana esta faceta del maestro de obras que contrataba simultáneamente diversos proyectos arraigaría en la siguiente generación de artífices. Destacaron así figuras como Jaume Llombart, cuyas primeras referencias laborales como maestro se remontan a su intervención en el Palacio del Real entre I447 y I460. El 2I de abril confeccionó «una docena de escabeles de madera de pino gruesa con las enseñas reales esculpidas, de largo de tres palmos cada uno [...] para la cámara del Consejo Real del Señor Rey», un trabajo enfocado al diseño y fabricación de mobiliario ${ }^{87}$. Simultáneamente, aparece como responsable de las obras de carpintería en la construcción de la Capilla Real en el convento de Santo Domingo, cuya experiencia le brindó la oportunidad de consolidar las habilidades adquiridas. Al frente de este proyecto emprendió una decidida faceta empresarial, siendo el principal proveedor de madera. Por ello, cuando en noviembre de I449 se planteó la cubrición de la sacristía suministró las piezas necesarias para los andamios del interior, junto al carpintero Antonio Batlle elaboró las cimbras y proporcionó la docena y media «de clavos redondos de madera de Ibiza largos» para ensamblarlas $^{88}$. El I2 de septiembre de I449 ideó y erigió la grúa vertical necesaria para la cubrición de la sala, para la que aportó los materiales, las poleas y el juego de cuerdas que sostenían «el tablón para subir la manobra, arriba a la capilla» ${ }^{89}$. Un sentido distinto tenía la provisión de madera del 3I de diciembre de I450 para las puertas de la sacristía, donde se guardaban las herramientas de la obra, aunque su faceta como escultor la descubre la talla más lujosa de la puerta principal, encargada el 4 de junio de 1462 por I50 sueldos ${ }^{90}$.

Su paso por esta fábrica constituyó un período de intenso trabajo en el que realizó tareas de talante muy diverso, que le permitieron mostrar su competencia en las artes del diseño a través de una interesante actividad como ingeniero ${ }^{91}$. Como maestro carpintero, fue el responsable del suministro regular de madera, de modo que su escasez no retrasara en ningún momento el progreso de las operaciones. Así, al disponerse a cubrir la capilla en febrero de I454, proporcionó para el andamio «diez maderos llamados mejorías, que son seis cargas y dos tercios de carga, para hacer cimbras y andamios para hacer la bóveda del frente de la dicha capilla,

87. Sanchís Sivera, J.: Pintores Medievales en Valencia. Barcelona, Estudis Universitaris catalans, 1914, p. 26.

88. ARV, Maestro Racional, 9.250 bis. Citado por TolosA, L. \& Vedreño, M.C.: Documents, en ZaragozÁ CatALÁN, A.: La capella reial d'Alfons el Magnànim de l'antic monestir de predicadors de Valencia. València, Direcció General de Promoció Cultural, Museus i Belles Arts, 1997, vol. II, p. 73.

89. ARV, Maestro Racional, 9.250 bis. Citado por TOLOSA, L. \& VedREÑO, M.C.:op. cit., p. 72.

90. ARV, Maestro Racional, 9.250 bis. Citado por TOLOSA, L. \& VedREÑO, M.C.:op. cit., p. 77.

91. Es manifiesto aquí el perfil profesional del maestro de obras, característico del arquitecto español del XVI, a través del ejercicio de una de las tres posibles vías de formación señaladas por Fernando Marías, la de los artesanos que superaban a sus homólogos gracias a la práctica del diseño arquitectónico que les permitía adquirir unas bases teóricas más sólidas y rebasar los márgenes estrechos de las competencias del oficio. Se recomiendan las reflexiones de Marías, F.: La arquitectura del Renacimiento en Toledo (1541-1631). Toledo, Instituto Provincial de Investigaciones y Estudios Toledanos, 1983, p. 84-95. 
a fuero de ciento cinco sueldos por carga que valen setecientos sueldos ${ }^{92}$. Para el transporte de estos troncos comprados en la Rambla al carpintero Joan Bot, actuó como carretero junto a Joan Asensi ${ }^{93}$. Incluso una vez descargados, se repartió el trabajo de aserrarlos junto al carpintero Francisco Selma. Estas labores descubren además el uso de esclavos en la carpintería medieval, porque Jaume Llombart se dividía la faena «por su sierra con dos esclavos por serrar madera de olmos y álamos blancos para hacer tablas» ${ }^{94}$. El 8 de marzo de I457 aportó la partida más importante de madera, la necesaria para el retablo que Ferrando Gosalbo debía esculpir para el altar, además de otras cuatro vigas gruesas para el trasaltar para «apoyar en ellas el retablo» ${ }^{95}$. El seguimiento de los trabajos en la Capilla Real del Convento de Santo Domingo consiente reconstruir el proceso de edificación e identificar la intervención de la carpintería, discernir entre los gastos en salarios y en materiales, conocer el tipo de máquinas y grúas ideadas, así como detallar las tecnologías empleadas en la arquitectura gótica ${ }^{96}$.

La contribución del diseño a la definición de la figura del arquitecto fue un proceso gradual al que contribuyeron maestros de distintos oficios de la construcción. Un episodio clave de la evolución trazada fue el contrato el trazado de la Obra Nova de la Catedral firmado en exclusiva por el carpintero Gaspar Gregori en 1566 como «arquitecto», porque el picapedrero Miquel Porcar, con quien erigiría la obra, no sabía escribir ${ }^{97}$. Si bien esta noticia pertenece a una fase avanzada del itinerario descrito, es crucial para esclarecer la formación de los artistas y valorar hasta qué punto calaron las nuevas corrientes humanistas en la realidad cotidiana del trabajo. Pese a las dificultades para estudiar los canales de transmisión en el obrador del artesano medieval, es innegable que la perspectiva analítica y el cálculo de las proporciones constituían la base de la preparación técnica de los planteamientos constructivos. Si bien es cierto que el artesano podía aplicar los principios elementales de manera rígida y mecánica, la variedad de las soluciones estructurales ideadas revelan que los principios básicos de la geometría y la técnica agrimensora se interpretaron con una originalidad que requería algo más que una mera percepción espontánea ${ }^{98}$.

92. ARV, Maestro Racional, 11.639. Citado por TolosA, L. \& Vedreño, M.C.: op. cit., p. 103.

93. La «milloria» era una pieza de madera equivalente a la mitad de una carga, de un tocho o jácena. Sobre la clasificación de los troncos según el marco valenciano, véase IZQUIERDO ARANDA, T.: op. cit., 2014, p. 261.

94. ARV, Maestro Racional, 11.639. Citado por TolosA, L. \& VEDREÑo, M.C.: op. cit., pp. 107-108.

95. ARV, Maestro Racional, 11.643, f. 82 v-87 v. Citado por TolosA, L. \& Vedreño, M.C.: op. cit., p. 176. En esta comisión compartía con el escultor la responsabilidad de la colocación una vez acabada la obra. El coste total desvela la cantidad de madera que requería la confección de un retablo de madera, desde el ensamblaje de las tablas y el marco a la talla de las imágenes.

96. IzQuierdo Aranda, T.: op. cit., 2014, pp. 256-265. El capítulo «Anàlisi de la tecnologia aplicada: la fusteria en la construcció de la Capella Reial del convent de Sant Domènec de València» analiza en detalle la tecnología y las estructuras empleadas en esta obra bajo la dirección de Jaume Llombart.

97. Sanchís Sivera, J.: op. cit., 1909, p. 68. Contrato registrado el 17 de julio de 1566 en el Llibre de Provisions del notario Joan Alemany, primer volumen número 3.640.

98. СомвA, R.: «Manodopera, maestranza, organizzazione del lavoro dei cantieri edili», en BoccHI, F. (coord.): I portici di Bologna e l'edilizia civile medievale. Bologna, Grafis Edizioni, 1990, pp. 95-97. 


\section{CONCLUSIONES}

En la orientación colectiva de los oficios de construcción es interesante observar el itinerario de cada sector implicado, ya que el desarrollo del proyecto dependía en buena manera de las condiciones de trabajo, los métodos de producción y de la evolución técnica de cada especialidad. En el caso concreto de carpinteros y albañiles hemos recorrido esta trayectoria, para estudiar la participación de la carpintería en la construcción y observar los lazos que justificaban su adscripción inicial a una misma corporación de oficio y constatar los cambios graduales que desembocaron en el progresivo alejamiento del obrero de villa, que desde el primer cuarto del siglo XV mostró un decido empeño por lograr su autonomía. En el curso de este proceso, fue crucial la influencia de las nuevas corrientes estilísticas y la introducción de procedimientos inéditos, más precisos en el planteamiento arquitectónico, que permitieron la aparición de un nuevo concepto de maestro constructor: el artífice privilegiado por su instrucción en diseño, cálculo y geometría, que le permitió diversificar sus empeños y ejercer como arquitecto. En la carpintería, la habilidad creciente en trabajos de talla y marquetería hizo evolucionar un repertorio todavía gótico para abordar las nuevas posibilidades de expresión aportadas por la conquista de la profundidad y el ilusionismo. Inscritos en la disciplina de los oficios de la carpintería, maestros constructores y escultores fueron abarcando paulatinamente campos de producción más diversificados, desde construcciones monumentales a marcos de retablos ricamente esculpidos y dorados ${ }^{99}$. Como se demostraría a lo largo del siglo xvı, la experiencia diaria en la obra y la práctica en el diseño fueron los dos puntales que consintieron al carpinteo medieval su promoción como arquitectos.

99. CeCCHI, A.: «L'Arte dei Legnaioli in Firenze: gli esordi», en AA.vV.: La grande storia dell'Artigianato. I/ medioevo. Firenze, Giunti, vol. I, 1999, p. 216. Comprendidos en el «Arte dei Legnaioli» o en el llamado «Arte dei Maestri di Pietra e di Legname», en Italia los maestros ebanistas dieron un verdadero salto cualitativo, al traducir en superficies lígneas diseños proporcionados por artistas del relieve de Maso Finiguerra, Alesso Baldovinettti o Sandro Boticelli mediante la combinación de láminas de madera de diversas especies y tonalidades. 


\section{Dossier Cómplices Necesarios por Carlos Reyero Hermosilla - Dossier Necessary Accomplices by Carlos Reyero}

2) CARLOS REYERO

Introduction: Necessary Accomplices / Presentación: Cómplices necesarios

25 Encarna Montero Tortajada

The Oligarch and the Brushes: a Biographical Sketch of Andreu Garcia, priest / El oligarca y los pinceles: breve semblanza del presbítero Andreu Garcia

María Alegra García García

Some aspects about archbishop of Toledo don Juan Martínez Silíceo's iconography (c.1477-1557) / Algunos aspectos en torno a la iconografía del arzobispo de Toledo don Juan Martínez Silíceo (c.1477-1557)

\section{FELIPE PEREDA}

Performing Doubt: the Art of Believing in Early Modern Spain / El ejercicio de la duda: el arte de creer en la España alto Moderna

\section{Jesús-PEdRo LoREnTE LORENTE}

The mouseion ideal reinterpreted as art colony on the outskirts of Darmstadt and Hagen / El ideal del mouseion reinterpretado como colonia artística en las afueras de Darmstadt y Hagen

\section{9}

NÚRIA FERNÁNDEZ RIUS \& NURIA PEIST

The photographic and the mediation system. Artistic, technical and commercial values in the beginning of photography / Lo fotográfico y el sistema mediador. Valores artísticos, técnicos y comerciales en los inicios de la fotografía

\section{Elena Marcén Guillén}

Real museum, imaginary museum. Considerations around the concept of museum as metamorphosis scenery / Museo real, museo imaginario. Reflexiones en torno al concepto de museo como escenario de metamorfosis

147 VICENÇ FURIÓ

Fame and prestige: necessary and decisive accomplices in the case of Hilma af Klint / Fama y prestigio: cómplices necesarios y decisivos en el caso de Hilma af Klint

\section{Miscelánea $\cdot$ Miscellany}

De la aljama a la primitiva construcción gótica. Reflexiones a propósito de la Catedral de Jaén en época bajomedieval / From the Great Mosque to the former Gothic construction. Some observations on Jaén's Cathedral during the late middle ages
199

TERESA IZQUIERDO ARANDA

Carpintero y maestro constructor en la arquitectura gótica valenciana / Carpenters and building mason in the Gothic architecture in Valencia $\left(14^{\text {th }}-15^{\text {th }}\right.$ centuries)

223

ANTONIO JosÉ DíAZ FERNÁNDEZ

El arquitecto madrileño Pedro de la Torre en Toledo y un retablo inédito localizado / The Architect of Madrid Pedro de la Torre in Toledo and a located unpublished altarpiece

24.7 Fernando R. Bartolomé García \& Laura Calvo García

Transformaciones en el retablo mayor de San Miguel Arcángel de Lazkao (Gipuzkoa). Del Barroco al Neoclasicismo / Changes in the main altarpiece of Saint Michael the Archangel in Lazkao (Gipuzkoa). From Baroque to Neoclassicism

\section{Francisco JaVIER LÁZARO SEBAStiÁN}

La renovación de la fotografía española a partir de la pauta estética del realismo. Un precedente formal y significativo en el reportaje de Eugene Smith sobre Deleitosa (Cáceres) / The renovation of the Spanish photography from the aesthetic guideline of the realism. A formal and significant precedent in Eugene's Smith photographic article on Deleitosa (Cáceres)

277 Javier Cuevas del Barrio

El posicionamiento de Sigmund Freud ante el Surrealismo a través de la correspondencia con André Breton / The position of Sigmund Freud regarding Surrealism through correspondence with André Breton

295 Alicia SÁnCHEZ ORTIZ

El vacío iluminado del negro / The illuminated void of black

317 Óscar MuÑoz Sánchez

Santiago Serrano (1970-1980): Hacia una pintura no aprehensible / Santiago Serrano (1970-1980). Towards a non-apprehensible painting

347 Antonio Jesús Sánchez FERnÁndeZ

Restauración y metamorfosis de los valores del patrimonio cultural / Restoration and Metamorphosis of the Values of Cultural Heritage

\section{Reseñas · Book Review}

375

Aricò, Nicola. Architettura del Tardo Rinascimento in Sicilia. Giovannangelo Montorsoli a Messina (1547-57). Firenze, Leo S. Olschi Editore, 2013. (AlICIA CÁmARA MuÑoz)

Combalía, Victoria. Dora Maar. Barcelona, Circe, 2013. (AMPARO SERRANO DE HARO)

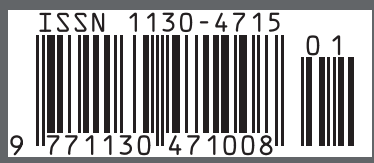

